\title{
UN EJEMPLO DEL ROMÁNICO INICIAL EN ÁLAVA: EL ÁBSIDE CON MODILLONES DE ORNAMENTACIÓN BIFACIAL EN NUESTRA SEÑORA DE ELIZMENDI, KONTRASTA
}

\author{
José Javier López de Ocáriz Alzola \\ Universidad de La Rioja
}

\begin{abstract}
RESUMEN: El objeto de estudio es una ermita situada en el valle de Arana, al oriente de Álava, junto a Navarra. En su entorno y muros predomina el contexto funerario, con lápidas romanas y tumbas altomedievales. Su interés arquitectónico y escultórico radica en el ábside de robustos sillares, donde se adivina una aspillera cegada aún inédita, y se exhiben diez modillones, originales por su perfil abombado y sus relieves bifaciales. Junto a tallas de diseño geométrico, similar al de las estelas discoideas, se ve un ingenuo Crucificado y el prótomo voluminoso de un lobo. La iglesia formó parte de un monasteriolo donado en 1203 por doña Sancia Pedriz de Uztuniga al Monasterio de Irache, cuando contaría un siglo aproximado desde la construcción del ábside estudiado. Puede valorarse como una primicia entre los más antiguos testimonios del románico de Álava.
\end{abstract}

Palabras clave: Románico, modillones, modillones de rollos, estela discoidal, ábside románico, aspillera, Cristo crucificado, lobo, rueda helicoidal, hexapétala, Elizmendi, Kontrasta, Álava, Edad Media.

\section{UN EXEMPLE DE L'ART ROMAN INITIAL EN ALAVA: L'ABSIDE ORNÉE DE MODILLONS À DOUBLE FACE. CHAPELLE NUESTRA SEÑORA DE ELIZMENDI, KONTRASTA}

RÉSUMÉ: L'objet de cette étude est une chapelle placée dans la vallée d'Arana, à l'extrême orient d'Alava, jouxtant la Navarre. Dans son environnement, et surtout insérées dans les murs, un bon nombre de stèles romaines et de tombes médiévales lui confèrent un contexte funéraire très particulier. Par rapport à son architecture et au programme décoratif, I'attention se pose sur l'abside maçonnée en moellons équarris, où l'on devine une rayère bouchée encore inédite, et l'on 
admire dix modillons très originaux d'après leur profil galbé et leurs reliefs à double face. Des dessins géométriques, semblables à ceux des stèles discoïdales, voisinnent avec un relief très naîf de Christ crucifié et avec le protomé saillant d'un loup. L'église faisait partie d'un petit monastère, qui avait été offert en donation au Monastère d'Irache par domna Sancia Pedriz de Uztuniga en 1203 quand, un siècle avant, la construction de l'abside étudiée était en cours ou peut être déjà finie. Cette abside et ses modillons annoncent les prémices de l'art roman, et s'avèrent figurer parmi les plus anciens témoignages d'Alava.

Mots clés: Art roman, modillons, modillons à copeaux, stèle discoïdale, abside roman, rayère, Christ crucifié, loup, roue hélicoïdale, rosace à six lobes, Elizmendi, Kontrasta, Alava, Moyen Âge.

\section{Introducción}

La floración de iglesias románicas en Álava es un hecho comprobado, aunque una mayoría de las estructuras y relieves apuntan a fechas avanzadas, en una fase de inercia, del siglo XIII. La comprobación documental y arqueológica de la existencia de núcleos de población antes del año 1000, y la lista de los nombrados en el documento de la Reja poco después de esa fecha, confirman la existencia de algún tipo de edificaciones, aún sencillas, dedicadas a las funciones de culto. Esa fase previa ha dejado elementos residuales: iglesias de eremitorios rupestres, restos de las bases de muros, altares, ventanas del tipo celosía o aspiIlera, estelas, algunos epígrafes y tumbas. La representación figurativa es uno de los factores ausentes en la fase previa al arte románico, como si los modelos y técnicas, que fueron habituales en el mundo clásico, hubieran sido soterrados' ${ }^{1}$.

Ese es el contexto en que tratamos de analizar un ejemplo de particular interés dada su situación, su implantación en un trasfondo funerario romano, su potente estructura absidial y sus más que originales modillones. Probablemente

1. PORTILLA VITORIA, M.J., et al., "La Llanada Alavesa Oriental y valles de Barrundia, Arana, Arraya y Laminoria", Catálogo Monumental de la Diócesis de Vitoria, V, Vitoria, 1982, pp. 377-391. PORTILLA VITORIA, M.J., "Arte románico. Raíces y evolución", col. Alava en sus manos, t. 4, Vitoria-Gasteiz, 1983, pp. 41-72, en particular las pp. 45, 48, 59, 70. VEGAS ARAMBURU, J.I., "Románico en Álava. Itinerarios para su visita y conocimiento", Cuadernos de Sección. Artes Plásticas y Monumentales, no 4, Eusko Ikaskuntza, 1986, pp. 47-61. LÓPEZ DE OCÁRIZ ALZOLA, J.J., MARTíNEZ DE SALINAS, F., "Arte prerrománico y románico en Alava", Eusko-Ikaskuntza. Cuadernos de Sección: Artes Plásticas y Monumentales, San Sebastián, 1988, pp. 15-79. LÓPEZ DE OCÁRIZ ALZOLA, J.J., Pays Basque Roman, col. «La nuit des temps», no 87, ed. Zodiaque, La Pierre-qui-Vire, Vauban, 1997, pp. 59 y 67. ESQUÍROZ ALBIZU, R., "Kontrasta", en LÓPEZ DE OCÁRIZ ALZOLA, J.J. (Coord.), Euskal Erromanikoaren Entziklopedia Enciclopedia del Románico en el País Vasco, II, Aguilar de Campoo, 2011, pp. 923-928. 
son estos últimos quienes más luz podrán arrojar, a la hora de plantear interpretaciones y de trazar conclusiones respecto a su significado histórico y artístico.

Al estudiar la ermita de Nuestra Señora de Elizmendi de Kontrasta afrontamos un caso algo atípico y complejo, cuya resolución se hace más difícil por la escasez de referencias históricas y de paralelos artísticos. Como otros ejemplos rurales, encaja en la problemática típica de la pequeña historia, del Ilamado arte popular propio de un lugar aislado en la montaña. Tanto Braudel como Chaunu han subrayado la relación entre el hombre y su obra construida para techo o para colmar sus necesidades y referencias vitales. Muchas veces se ha citado a Pierre Chaunu retomando su alusión a que la construcción era la más importante de las actividades no agrícolas de la economía tradicional europea. Pero una inmensa mayoría de lo construido durante siglos ha desaparecido sin dejar rastro².

Ante las dificultades del estudio de estructuras simples, indocumentadas, y con ornamentación simple e inercial, partiremos de una observación cuidadosa, con una descripción detallada, para pasar a un análisis de las referencias más significativas. Los procedimientos y tipo de talla pétrea ofrecen en el entorno ejemplos de una perduración milenaria, desde las lápidas romanas a la inveterada tradición de las estelas discoideas, pasando por los modillones que estudiamos ${ }^{3}$.

\section{Emplazamiento y situación. Datos arqueológicos, geográficos e históricos básicos}

La ermita de Nuestra Señora de Elizmendi ${ }^{4}$ se sitúa en un altozano, al sur de la villa de Kontrasta. Esta villa se halla en el extremo oriental del territorio

2. CHAUNU, P., "Le batiment dans l'économie traditionelle", en Le bâtiment: enquête d'histoire économique, XI-XVe siècles, Paris/La Haye, EHESS, 1971, p. 19.

3. Es una piedra más en el camino de la longue durée, la expresión acuñada por Fernand Braudel para caracterizar esas corrientes profundas y silenciosas cuyo sentido solo se comprende tras recorrer una dilatada secuencia temporal. El historiador subraya el peso de ciertas estructuras que ralentizan el ritmo de la emancipación y de la evolución humana. Decía Braudel: Piénsese en la dificultad de romper ciertos marcos geográficos, ciertas realidades biológicas, ciertos límites de la productividad, y hasta determinadas coacciones espirituales: también los encuadramientos mentales 'sont prisons de longue durée': "son prisiones de larga duración". BRAUDEL, F., Histoire et sciences sociales: La longue durée, en Annales. E.S.C., 4, 1958, Débats et Combats, pp. 725-753, traducido en: La Historia y las Ciencias Sociales, Madrid, Alianza, $7^{\text {a }}$ ed. 1984, pp. 70-71.

4. Respecto de la denominación de Elizmendi, su traducción desde el euskera no tiene dificultad: iglesia en el monte, o la iglesia del monte, mejor que el monte de la iglesia, confirmado por el lingüista Luis MICHELENA: "Algunos nombres de Contrasta", en Anuario del Seminario de Filología Vasca "Julio de Urquijo", Donostia-San Sebastián, t. 19, n. 2, 1985, pp. 595-602. Señala en p. 600: Nuestra Señora de Eizmendi, voz vascongada, que en castellano vale lo mismo que Iglesia del Monte, y recoge en la p. 602 varios términos relacionados: De el(e)iza tenemos, en los casos seguros, además de uno ya presentado, Elizmendi, Elizmendialdea, Elisostea, al lado de Elesmendi, 1759. 
alavés, coronando, desde su altura de $828 \mathrm{~m}$, un típico valle de montaña, así denominado en euskera: Arana, el valle. Desde sus cumbres envuelven a Kontrasta, por el norte el monte Murube $(1135 \mathrm{~m})$, desde el noroeste el Alto de San Cristóbal (1145 m), y por el sur la peña de Arnaba (1258 m). Sus tierras son colindantes con las navarras de la Ameskoa Alta: Larraona, Aranaratxe, Eulate y Zudaire, situadas entre la sierras de Entzia-Urbasa al norte y la de Lokiz al sur. Desde allí bajan las aguas del Urederra hacia Estella, que dista menos de $35 \mathrm{~km}$ de Kontrasta, poco menos de la distancia de Vitoria, que es de unos $42 \mathrm{~km}$.

El poblamiento de la comarca de Arana ofrece testimonios desde la prehistoria, pues en el entorno se han localizado áreas megalíticas, además del enterramiento bajo roca de Lamikela, reconocido por D. José Miguel de Barandiarán en 1933 como del Bronce final (Carta Arqueológica, no 5063), o las sepulturas de la cueva de Obenkun, próximas a la ermita de Santa Teodosia, descubiertas por D. Domingo Fernández Medrano en 1934, e igualmente atribuible al Bronce I/II (Carta Arqueológica, no 5053). También constan varios hallazgos sueltos, como un hacha pulimentada (Carta Arqueológica, no 5593), y una estela discoidea ornamentada con cruz, aislada en el término de Iralacha, que al localizarla yo mismo en 1981 y, dado el riesgo de deterioro o de robo, logré poner inmediatamente a salvo en el Museo de Arqueología (Carta Arqueológica, no 324). Lo más significativo es el conjunto de 25 lápidas o estelas romanas intestadas en la misma ermita que estudiamos ${ }^{5}$.

La ermita se halla situada en ambiente montañoso, una típica zona marginal. De ahí se deduce su previsible aislamiento en la época de construcción respecto a centros activos en lo cultural, económico, religioso y político. Pero un dato muy revelador rompe el aislamiento y el vacío documental. Ha quedado constancia de la existencia con su nombre de un monasteriolo, de patronato laico, que una poseedora, portadora de apellido navarro fronterizo con Álava, entrega a Irache.

Tal como consta en el Archivo General de Navarra, procedente del Cartulario de Irache ${ }^{6}$, se fecha en 1203 la donación que hace al Monasterio de Santa

5. AAVV, Carta Arqueológica de Alava. 1 (hasta 1984), Vitoria-Gasteiz, 1987. En esta carta se ofrece una lista de 25 estelas y lápidas romanas intestadas en la ermita de Elizmendi, los nn.: $66,67,68,69,70,71,72,324,5063,5593,9020,9021,9022,9023,9024,9025,9026,9027$, 9028, 9029, 9030, 9031, 9032, 9122, 9128, 9134. Descontamos de entre ellas el no 9122, pues coincide con el $\mathrm{n}^{\mathrm{o}} 5$ de los modillones que sostienen el alero de la ermita, y en ese caso creemos que se establece una interpretación errónea como si se tratase de un fragmento recortado de una estela romana. Aludiremos a ella en su condición de modillón románico.

6. Colección Diplomática de Irache, siglos X-XIII: (Bec. Ir., f. 91r-92v. Lo citaba ya José María Lacarra en su edición de la "Colección Diplomática de Irache", Vol. I (958-1222), en Fuentes para la Historia del Pirineo, no IV, Zaragoza, Universidad de Navarra, CSIC, 1965. EI 
Maria la Real de Irache domna Sancia Pedriz de Uztuniga de las tres partes que tenía en el monasterio de Santa María de Elizmendi, además de varias casas, solares, heredades y diezmos. La fecha de 1203 es un indicativo ante quem, por lo que podemos suponerle un tiempo precedente de existencia al pequeño monasterio y a su iglesia, sin poder precisar cuánto ${ }^{7}$.

Pese a ser zona algo inhóspita, por montañosa y fría, resultaba en tiempos conflictivos una valioso zona de paso resguardado, y quizá con importancia estratégica en contextos políticos puntuales, al tratarse de un secular punto de frontera. El emplazamiento también resulta significativo. Asoma en lo más alto de un collado que domina un pequeño valle, con caminos que cruzan hacia el sur, norte y este.

La villa de Kontrasta recibió de Alfonso X, rey de Castilla, el 12 de octubre de 1256 el mismo fuero y privilegio que había sido concedido a Vitoria en 1181 por el rey Sancho el Sabio de Navarra. Entre otras mercedes enriqueñas, Kontrasta fue entregada a Ruy Fernández de Gauna, según privilegio rodado, fechado el 12 de mayo de $1370^{\circ}$. Una de sus descendientes, doña Elvira de Gauna, casó a mediados del siglo XV con Juan López de Lazcano. En palabras de Lope García de Salazar, los Lazcano, eran: cabeza e mayor del linaje de Oñiz e más rico de rentas de toda Guipúzcoa; y destacan como uno de los máximos representantes del bando oñacino, enfrentado al de los gamboínos.

Becerro de Irache, códice en pergamino escrito en el siglo XIII, recopila documentos hasta el abad Sancho (1181-1222).

7. El documento señala que dona: tres partes quas habeo in illo monasterio...cum decimis et oblacionibus et cum suis terris, uineis et ortalibus, molendinis, pratis, pascuis uel montibus, heremo et populato, aquis et cum omni introitu et exitu, (las tres partes que poseo de aquél monasterio... con sus diezmos, ofrendas, y con sus tierras, viñas y huertos, molinos, prados, pastizales y montes, yermo y poblado, aguas, y derechos de entrada y salida). Cita una posesora que tiene como apellido compuesto Elizmendi, indicio de antigüedad del solar: Solares de Goto Sanz de Elizmendi. Como testigo se indica el nombre del capellán: Martinus capellanus sancte Marie de Elizmendi y lo confirma todo el concejo de Elizmendi. Todo muestra un inveterado arraigo del "monasterio" de Elizmendi en 1203, es decir que inclina a pensar que llevaba varias generaciones como institución y como construcción.

8. MADOZ, P., Diccionario geográfico-estadístico-histórico de España y sus posesiones de ultramar, Madrid, 1845-1850, (reed. Vitoria, 1989), pp. 113-114: Contrasta se mantuvo realenga hasta que D. Enrique Il la dio á Ruy Fernandez de Gauna, alférez mayor de Castilla, después de la batalla de Nájera, en remuneración de sus servicios, particularmente por haber dado su cabaIlo al rey después de perdida aquella batalla. Esta anécdota fue recogida en la Crónica del Rey D. Pedro de 1367, escrita por D. Pero López de Ayala. También señala Madoz en p. 114: además de la parroquia de la Asunción otras ermitas en Kontrasta: San Cristóbal, San Vicente o Joandeneguendi, San Martín, San Esteban, Santa Cruz, Santa Maldea, San Salvador, y Ostia. Su número puede aumentarse siguiendo a LÓPEZ DE GUEREÑU, G., Alava, Solar de Arte y de Fe, Vitoria, 1962, con las de San Adrián, Santa Amalia, San Juan, y los términos de San Patricio y Santucoarana, y debe corregirse la última advocación de Madoz por la de Nuestra Señora de Oitia. 


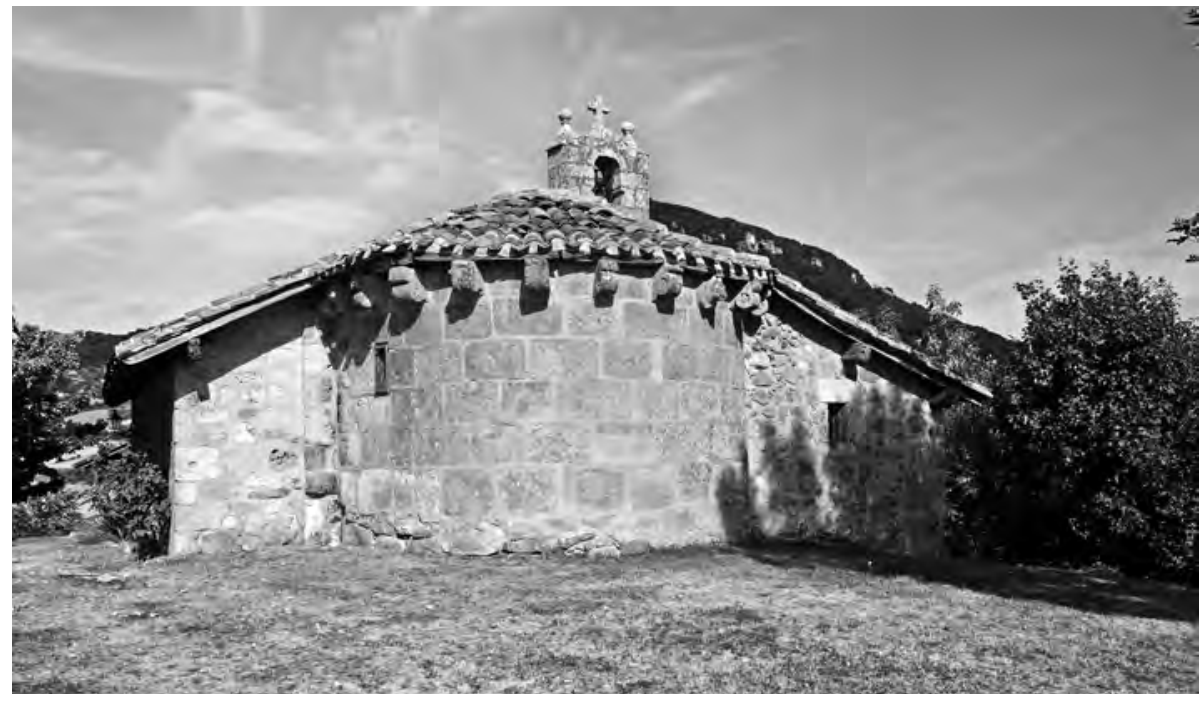

Lámina 1. Ermita de Nuestra Señora de Elizmendi: ábside.

\section{Estructura arquitectónica y aparejo del ábside}

La estructura que analizamos es simple y sólida, caracterizada por la forma, tamaño y aparejo del ábside. El ábside es la cabeza de la iglesia, su proa hacia oriente, la zona más sagrada. Por esa parte se inicia la construcción del edificio de culto. Por ello generalmente es lo más antiguo y, con la portada, lo más valorado, de modo que se mantiene y conserva, en muchos casos aún cuando el resto haya sido remodelado. Ese es el caso de Nuestra Señora de Elizmendi. Allí, el modelo de planta absidial adopta forma de exedra algo más abierta en la boca que en el arranque del semicírculo. Es conocido que los ábsides primitivos son muy limitados en espacio, tanto en anchura como en altura y que la tendencia posterior tratará de ampliar el espacio presbiteral añadiendo un tramo recto, y elevando la altura. En Elizmendi las dimensiones son muy reducidas; en el exterior: muro de 3,35 $\mathrm{m}$ de alto, 4,30 $\mathrm{m}$ de largo y $5 \mathrm{~m}$ de ancho, en el espacio interior: alto 3,6 m, 3,8 m de profundo, 3,2 $\mathrm{m}$ de ancho y 2,7 de luz del arco, aún teniendo en cuenta que el altar y los elementos añadidos restan precisión a algunas de las medidas ${ }^{9}$.

9. Una fotografía del ábside de Elizmendi, realizada hace más de un siglo, poco después de 1900, muestra un aspecto casi idéntico al actual. Corona el tejado la misma espadaña con remates de bolas y cruz, albergando su vano de arco con la esquila. Se reconocen los mismos sillares, aunque aún no están rejuntados, la ventana practicada hacia el sur, los ocho primeros modillones, probablemente las viguetas durmientes sobre ellos permanecen igual, la misma 
El cuerpo del edificio es una larga nave de mampuestos sin evidencias de antigüedad en su disposición. No hay duda de que se trata de una refección tardía, que no tienen nada que ver con el momento y concepción arquitectónica del ábside. Se abre así la incógnita sobre cómo pudo ser el proyecto o la estructura inicial completa. Puede servir como referencia la planta y alzados, allí completos, de la Andra Mari de Ullibarri Arana, ermita que solo dista unos $3 \mathrm{~km}$ de Elizmendi y cuenta con un ábside similar, algo mayor en tamaño.

Centramos el estudio en la tipificación del ábside, de escasa altura, compuesto por sillares bastante grandes y regulares. Los muros románicos, sean del ábside o del resto del templo, sobrepasan generalmente el metro de espesor, que aumenta en proporción al peso previsto de la estructura de carga. Según unas mediciones en el ábside de Elizmendi, tal previsión era modesta, pues el espesor que ha podido controlarse en sus muros se halla próximo a los $70 \mathrm{~cm}$. El limitado volumen exterior e interior parecen un signo de primitivismo y de simplicidad funcional. El muro delgado es un indicativo de que no estaban programados grandes pesos, como los que originaría una edificación elevada o un amplio abovedamiento. Visto en su interior, carece del tramo de presbiterio y abre a la nave por un sencillo arco triunfal.

En su costado septentrional, el perímetro del ábside fue alterado por una pequeña edificación habilitada para sacristía, añadida en época moderna, de modo que se reduce la visión completa del ábside y del conjunto de modillones. Por otro lado, sorprende encontrar unos modillones bastante más sólidos que los habituales canes, sosteniendo elementos más ligeros que las típicas cornisas románicas. La carencia de tales cornisas quizá pueda explicar que se confíe a los modillones la doble tarea sustentante de canes y cornisas.

El análisis de la composición del aparejo del ábside revela a simple vista una calidad de ejecución que resulta sorprendente. De las siete hiladas, las cinco

estructura de tejado, solo que en vez de estar las tejas afianzadas con masa, se muestran lastras de piedra para sujetarlas. Se adivina la posición del ventanal primigenio a modo de saetera, cegada, bajo el séptimo modillón. Lo único novedoso es la presencia de una cruz de madera colgada entre los modillones $4^{\circ}$ y $5^{\circ}$ : el del crucificado y el de la hexapétala y el disco helicoidal. Aún ahora se aprecia su huella más clara sobre los sillares superiores en ese punto. Una cruz similar se halla colgada ahora en el muro del extremo oeste, en la zona de los pies. Podemos por todo ello suponer que la apariencia actual del ábside se mantiene inalterada desde hace bastantes generaciones. CASTRO, C., Catálogo Monumental de España. Provincia de Alava, Madrid, 1915, El texto de las pp. 140-142 ofrece datos genéricos y por error atribuye a esta ermita el tríptico-retablo de Yurre. En cambio aporta como dato de interés en la lám 53, del lado izquierdo, una fotografía de más de un siglo, que nos asegura de la permanencia de su aspecto. Ya señalaba D. Elías Tormo que, de esta obra, las fotos eran lo único válido. En la fotografía aparece firmado: A. Ciazár Yto, bien se trate de un nombre o de un referente, pues en los pies de foto, las así firmadas son atribuidas en muchos casos a L. Elorza, y otras veces a Guinea, Larrañaga o a M. Ugarte. 
centrales mantienen su integridad, pues la inferior, quizá por erosión, ha debido ser recompuesta con sillarejo, y la zona entre canes se ha adaptado en forma de metopas lisas.

\section{La aspillera oculta}

Por razones prácticas, para obtener iluminación natural sobre todo en las misas matutinas, se hace necesaria al menos una ventana absidial: fenestra lucifera, que sucesivamente se hará acompañar de otras más. Cuando es única, su posición ocupa exactamente el centro del ábside. En Elizmendi pasa completamente inadvertida por su pequeño tamaño, por haber quedado cegada y porque carece de referencias arquitectónicas o escultóricas que la destaquen. Es una simple aspillera, y aunque el revoco oculta su forma, puede suponerse que es aún más primaria que el tipo de ojo de cerradura. Simplemente es una holgura entre dos sillares acomodada al espacio entre dos hiladas sucesivas. El retablo interior impide comprobar si abre en derrame hacia el interior, lo que parece necesario para una mínima iluminación, y probable por comparación con la Andra Mari de Ullibarri Arana. Pese al revoco, se aprecia una muesca en el sillar superior, es decir que se eleva algo más que los sillares y su remate es de forma curva.

$\mathrm{Su}$ apariencia es tan discreta que los estudios anteriores y los alzados que han dibujado el ábside han pasado por alto este humilde hueco de ventana. Es comprensible el olvido pues queda completamente disimulada, dada su estrechez, su adaptación completa a los niveles de hiladas, y que el revoco colma el hueco mimetizándola. Va encajada en el centro de la tercera hilada desde arriba, la quinta desde el suelo, es decir, entre los 2 y 2,50 m de alto aproximadamente. Se puede calcular que no sobrepasa los $57 \mathrm{~cm}$ de alto ni los $13 \mathrm{~cm}$ de ancho. Prácticamente parece una rendija más que una ventana. Cumple a la perfección las habituales razones de los angostos vanos románicos: no debilitar el muro, dejar pasar algo de luz, pero impidiendo el paso a humanos, animales, y al frío.

Su posición está centrada, debajo del modillón $8^{\circ}$, es decir el $7^{\circ}$ de los decorados. Si la organización se planteó de modo simétrico, podemos suponer que se dispusieron quince modillones, de los cuales al menos faltan cuatro en el espacio del muro oculto por el añadido tardío de una sacristía. Según referencias obtenidas en el pueblo de Kontrasta, por causa de goteras en esa zona de la sacristía hubo que levantar parcialmente el tejado y pudieron comprobar que había más modillones, pero no pudo proseguirse la obra, y se volvió a cubrir. También citaremos el hallazgo que hemos hecho en el muro exterior de esa sacristía, de los restos de un fragmento de disco pétreo, con el mismo diseño de rueda/cruz inserta en un círculo, que lo asemeja del todo a los modillones estudiados. 


\section{Canteras, aparejo y labra}

Salta a la vista la robustez y regularidad del aparejo en el ábside. Se disponen siete hiladas en un muro de 3,35 m de alto. Las dos superiores y la inferior -ésta más alterada y difícil de medir-, son las más delgadas, en torno a $45 \mathrm{~cm}$. La más gruesa es la 2a desde abajo, que llega a los $60 \mathrm{~cm}$, y las intermedias lo son también en espesor, acercándose a los $50 \mathrm{~cm}$. La longitud de los sillares es muy variable, desde el medio metro a más de un metro, destacando por su volumen varios sillares de la $2^{a}$ por abajo y de la $2^{\underline{a}}$ por arriba.

El número de sillares en la superficie visible del ábside oscila en torno a la docena por hilada. Calculando el conjunto inicial, incluyendo la parte oculta, podían alcanzar 16/18 por hilada, es decir que se necesitaban para el muro perimetral bastante más de un centenar de sillares bien acabados, adaptados al perfil curvo del ábside. Están también los destinados a la cara interna, al arco triunfal, más la labra de los modillones. Aunque no conocemos la disposición y envergadura del resto del templo, la realización del ábside exige un taller de cantería organizado y experto. Esa considerable tarea se agranda ante su falta de precedentes en el momento y en el lugar; es un inicio a partir de un total vacío constructivo. Desconocemos todo respecto a promotores y artesanos, pero en aquel pequeño lugar es el testimonio válido de una sólida estructura construida en un momento bisagra de la Edad Media.

La piedra utilizada es la caliza paleocena, cuyo color blanquecino ha quedado oscurecido por la pátina y los líquenes. Las canteras de probable extracción del litotipo están muy próximas, siendo conocidos en la sierra de Entzia los bancales de Zizama, que hacia el norte no distan más de $8 \mathrm{~km}$ de Elizmendi. Además, bastante próximos a los terrenos de Zezama o Zizama se halla la tradicional majada o aprisco de Kontrasta en esa sierra, Ilamada por eso: Kontrastako Saroia. La cantera de Zezama sirvió para la extracción de un mismo material realizando lápidas romanas, los modillones y sillares de Elizmendi o las estelas discoideas, es decir durante bastante más de un milenio ${ }^{10}$.

En la misma ermita de Elizmendi, donde se comprueba la reutilización de venticinco estelas o lápidas funerarias romanas, algunas de las más ostentosas se exhiben en el extremo sur del ábside, en el tramo que va desde la ventana tardía hasta el ensanche de la nave. Cabe la duda de si su acondicionamiento fue en la etapa inicial de construcción o si fueron añadidos en las reformas de la nave

10. MARTíNEZ-TORRES, L.M., "Arabako erromanikoko lititipoak, konposizio litologiko bakanak eta antzinako harrobiak. Litotipos, composiciones litológicas y canteras antiguas del románico alavés", en LÓPEZ DE OCÁRIZ ALZOLA, J.J. (Coord.), Euskal Erromanikoaren Entziklopedia - Enciclopedia del Románico en el País Vasco, I, Aguilar de Campoo, 2011, pp. 101116. En el mapa de la p. 103 aparecen indicados los puntos que identifican a Elizmendi y la Andra Mari de Ullibarri Arana. 
y en el retoque que supuso el incrustar la ventanita cuadrada para iluminar el presbiterio al cubrir el fondo del ábside con el retablo, sea el actual o uno anterior. También se observan varios fragmentos de lápidas similares, intestados en los muros de mampostería de la nave, por ejemplo en el dintel de la puerta.

La labra de la piedra es correcta, con sillares bien escuadrados. Se han afinado las caras de sillares y modillones, con superficies planas y ajuste exacto. Como es habitual, unas mismas manos labrarían sillares o el contorno de los modillones, y en éstos realizarían el grabado o talla de la decoración a fondo realzado. No hay ninguna previsión de secuencia de planos, más que una pura bidimensionalidad. La única excepción la constituye el bulto configurado para representar un prótomo zoomórfico, que es la máxima aportación del monumento a la escultura de bulto.

Ya hemos señalado que las hiladas muestran espesores algo desiguales, a la medida del bancal, e incluso los modillones a veces, si se comparan sus costados, muestran ciertas alteraciones en sus perfiles de corte. Algunas de las ornamentaciones admitirían un mayor rigor en la finura de su trazado, por ello sorprende la calidad excepcional del modillón $\mathrm{n}^{\circ}$ 4, que conjuga la hexapétala a un lado con la esvástica al otro, desplegando algunos detalles más finos y menudos en las orlas de la corona exterior.

No son muy acusadas las huellas del instrumental de talla, sea por haber recibido tratamiento igualador en el acabado, o por el difuminado debido al correr del tiempo. Dado el carácter franco de la caliza empleada, tras el desbastado, la fase de moldeado permitiría atacar en ángulo oblicuo, labrando la piedra con poco mayor esfuerzo que en una madera recia. Entre las huellas del modillón 2 en su cara norte, se identifica la huella alargada producida por cinceles de filo cóncavo y estrecho. En los lomos convexos de los modillones la huella es menos clara, pues parecen haber regularizado su superficie. No hemos observado ninguna huella de gradina o de hacha dentada en su corte. Para peinar los surcos de estrellas y esvástica, o vaciar círculos en los motivos grabados, sería necesaria una herramienta de corte preciso, seguramente un cincel de corte recto. Estos motivos, y sus técnicas de labra, derivan del mismo repertorio que a veces han empleado los carpinteros para personalizar ciertas obras talladas" ${ }^{11}$.

Los bloques de piedra requeridos para los modillones son de buen tamaño. En especial, las hiladas centrales aparecen compuestas a soga con destacada regularidad en cuanto a su alineación, y con el uso de sillares uniformes en su talla, en el escuadrado de ángulos y aristas, y semejantes en tamaño. En los elementos visibles, las medidas generales oscilan para el saliente horizontal entre

11. WITKOWER, R., La escultura. Procesos y principios, Madrid, Alianza, 1980. BESSAC, J.-C., L'outillage traditionnel du tailleur de Pierre de l'Antiquité à nos jours, éd. du CNRS, París, 1986. CAMÍ/SANTAMERA, Escultura en piedra, Barcelona, Parramón, 2000. 
los 32 y los $50 \mathrm{~cm}$, para la altura entre los 40 y $50 \mathrm{~cm}$, y para el espesor entre los 22 y $32 \mathrm{~cm}$. Se requieren, por tanto, bloques del tamaño de los más grandes empleados para labrar los sillares del muro, pero no de exageradas dimensiones. Pudieron elegir los más sólidos y proporcionados de entre las carretadas que Ilegaban para la construcción del ábside. Su aspecto, en material y labra, resulta similar a los sillares contiguos. Podemos suponer que, tanto unos como otros, fueron labrados a pie de obra, siempre avant la pose.

Al estar dispuestos los modillones de modo perpendicular respecto a los sillares del muro, funcionan de hecho en su hilada como un aparejo de soga y tizón, al que normalmente se atribuyen cualidades suplementarias de estabilidad. A partir de una construcción compacta, dada la escasa altura del muro, que no alcanza los 3,5 m, y el probable apoyo sobre material rocoso, se explica el buen mantenimiento de la estructura del ábside, en que no se aprecian grietas ni corrimiento de los materiales. La única parte dañada es la base, es decir la primera hilada, en que algunos sillares están fragmentados, por agresión de hogueras, o más probablemente debido a las humedades causantes del efecto azucarillo ${ }^{12}$.

En época románica será habitual para el corte de piedra en posición lanzada la escoda o trinchante, es decir una herramienta con forma de hacha, de corte lineal o dentado; en cuanto a la posición de corte impulsado por percutor, es decir, por un mazo o maceta, el uso de varios tipos de cincel es permanente en toda época. Respecto al cincel de filo cóncavo, fue empleado en la fase previa e inicial del arte románico. En cambio el empleo de trinchante dentado y de gradina, ya constatados en época clásica, solo se documenta una vez avanzado el siglo XIII' ${ }^{13}$.

\section{Descripción de los modillones ${ }^{14}$}

Los consideramos modillones, más que canes, porque difieren del formato característico de los canes cóncavos y ligeros propios del arte románico, donde la figuración se aloja en el hueco inferior. En cambio, los modillones estudiados subrayan el elemento central del volteo, con panza abombada y perfil discoidal, remitiendo los relieves a las caras laterales. Sorprende la robustez de su voluta frontal, puesto que solo soportan una ligera tablazón, a modo de tegui-

12. MARTíNEZ-TORRES, L.M., La tierra de los pilares. Sustrato y rocas de construcción monumental en Álava. Mapas litológicos de las iglesias de la Diócesis de Vitoria, UPV, Bilbao, 2004, p. 106.

13. BESSAC, J.-C., L'outillage..., pp. 92-99, 102-104, 117-154, 172-179, 183-185 y 287.

14. En cada modillón se precisa en centímetros las medidas siguientes: A: altura máxima del bloque a nivel del muro; B: máxima distancia del muro, que suele alcanzarse en el plano superior del modillón; C: anchura o grosor máximo del modillón; D: altura del rollo superior; E: altura del rollo medio; F: Altura de la moldura inferior, de carácter convexo si no se indica lo contrario. Cuando distinguimos las caras izquierda y derecha, nos referimos a las del espectador. 


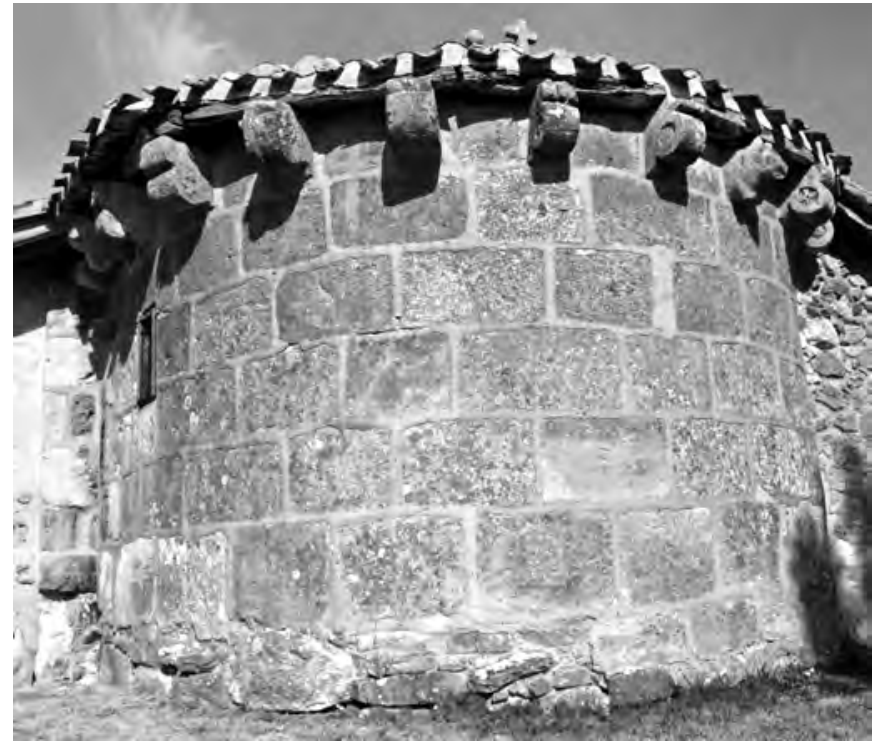

Lámina 2. Ermita de Nuestra Señora de Elizmendi: ábside.

Ilo, como apoyo de las lajas pétreas, que en su momento recibirán la cubrición de teja. De hecho los canes, de antigua raíz, triunfarán en el arte románico ${ }^{15}$.

Hacia el extremo meridional del ábside, junto al arranque del ensanchamiento de la nave, en vez de un modillón, se muestra como soporte del alero un bloque cúbico regular, sin forma especial, cuyas medidas son: $35 \mathrm{~cm}$ de alto, $28 \mathrm{~cm}$ de saliente del muro, y $28,5 \mathrm{~cm}$ de anchura. Casi debajo de él sobresale del muro un muñón pétreo más pequeño, sin función conocida. Un metro más adelante se ha rasgado el muro para albergar un ventanal tardío muy simple, que mide de alto $65 \mathrm{~cm}$ y $42 \mathrm{~cm}$ de ancho. En ese punto el muro muestra un espesor de $76 \mathrm{~cm}$.

15. En el patio central de la villa romana de "La Olmeda", Palencia, siglo IV, famosa por sus mosaicos, nueve arcos de $4 \mathrm{~m}$ de altura, como apoyo de una pérgola, conservan como remate del muro varios canecillos pétreos decorados con perfiles geométricos que recuerdan a las molduras de las basas áticas: una escocia entre dos toros. ABÁSOLO, J.A., MARTíNEZ, R., La villa romana de la Olmeda. Guía arqueológica, Diputación de Palencia, 2012. Especialmente en las pp. 19, 24 y 63 explican que esos arcos fueron reconstruidos según una precisa anastilosis y consideran que los citados modillones constituyen uno de los más antiguos testimonios conocidos de esa clase de voladizo, que siglos más tarde popularizará la arquitectura cristiana medieval. Los canes, elemento considerado tradicionalmente como menor dentro del arte románico, han ido cobrando creciente importancia. Uno de los acicates para el despegue correspondió al artículo de KENAAN-KEDAR, N., DEBIÈS, M.-H., "Les modillons de Saintonge et du Poitou comme manifestation de la culture laïque", Cahiers de civilisation médiévale. 29e année, ํㅜㄴ 116, 1986. pp. 311-330. 
El modillón $\mathrm{n}^{\mathrm{0}}$ 1: muy similar al siguiente, se caracteriza por sus molduras convexas, destacando dos grandes rollos, siendo más sobresaliente y destacado el toro superior. Además, como tercera moldura, consta de una pequeña gola hacia la base. No presenta decoración. Medidas del bloque saliente: A: 41; B: 50; C: 32; D: 21; E: 12; F: 8.

Modillón $n^{\circ}$ 2: de las dos molduras convexas es más saliente la superior, pero resulta un poco más abultada la segunda. Hacia la base se muestra una pequeña gola. No presenta decoración. Medidas del bloque saliente: A: 46; B: 39; C: 22; D: 19; E: 21; F: 6.

Modillón no 3 : también de las dos molduras convexas es algo más saliente en comba la superior, pero resulta más abultada la segunda, reposando sobre una pequeña gola. El bloque del modillón se ensancha netamente en la base. Secundando la curva de la segunda moldura, presenta decoración en la cara izquierda. Se trata de un círculo con el fondo rebajado y destacando sobre él una estrella de ocho radios tallada a bisel. El diámetro del círculo mide $13 \mathrm{~cm}$, y cada radio $6,5 \mathrm{~cm}$. Medidas del bloque saliente: A: 46; B: 37; C: $31 ; \mathrm{D}: 18,5 ; \mathrm{E}: 22 ; \mathrm{F}: 5,5$.

Modillón no 4: es una composición diferente, potenciando el resalte del gran disco central, flanqueado arriba por una delgada comba y abajo por una moldura en forma de gola. Ostenta decoración en ambas caras, ofreciendo especial interés la del costado izquierdo. Medidas del bloque saliente: A: 46; B: 41; C: 24; D: 3; E: 38; F: 5.

Cuando observamos desde nuestra izquierda la cara del modillón encontramos la figuración más expresiva del conjunto. Se reconoce una figura humana muy estilizada, de rasgos que consideramos primitivos. Se ha tallado sobresaliendo en bajorrelieve de unos 3 a $4 \mathrm{~cm}$ de bulto. Antes de su desgaste y deterioro el saliente pudo ser mayor. En su anatomía se ha destacado la cabeza, manos y piernas. Rodea la cabeza un nimbo, rematado por arriba en un saliente trapezoidal de hasta $6 \mathrm{~cm}$ de alto. Imaginamos que sugiere el cabezal vertical de la cruz, aunque el resto de ella no se muestra. Si quisiera aludir al vástago superior del nimbo crucífero, debería incluirse dentro del nimbo y no sobre él. No se aprecian los otros dos vástagos horizontales a ambos lados de la cabeza. El nimbo alcanza un diámetro máximo de $11 \mathrm{~cm}$, envolviendo una oquedad, único resto de la cabeza, que mide $7,5 \mathrm{~cm}$ de alto por $6 \mathrm{~cm}$ de ancho. Es una lástima que algún arrebato iconoclasta haya privado de expresión a la figura.

Bajo un breve cuello se prolonga un tronco esbelto ensanchado a partir de la cadera, diferenciando ambas piernas con línea mediana en una silueta acampanada. No se distinguen los pies, que alcanzarían el borde inferior del bloque redondeado. Se ha potenciado la horizontal de los brazos, que abarcan hasta $31 \mathrm{~cm}$, pero el predominio visual corresponde a las manos, cada una de $10 \mathrm{~cm}$ de longitud y de $7,5 \mathrm{~cm}$ de ancho. La altura total de la figura es de $39 \mathrm{~cm}$, de los que casi la mitad, $17 \mathrm{~cm}$, corresponden a cabeza, nimbo y remate de la 
cruz, mientras el tronco y piernas ocupan los 22 cm restantes. La combinación ajustada entre horizontal y vertical, encuadrada en diseño circular, recuerda -salvando las distancias- el esquema vitruviano, popularizado por el dibujo de Leonardo da Vinci.

El deterioro y hundimiento de la cabeza ha trasladado el punto de referencia a la mano diestra, con palma y dedos mejor detallados, quizá simplemente por la protección del alero, de la que no disfruta la mano izquierda, muy desgastada. De modo intencionado o casual, es la diestra quien focaliza la atención, animando discretamente el carácter de una efigie tan desfigurada ${ }^{16}$.

El bloque pétreo de este modillón no 4 presenta como peculiaridad un desnivel en su cara curva frontal, pues la segmenta en dos partes, con anchura de 7 $\mathrm{cm}$ la izquierda y de $13 \mathrm{~cm}$ la derecha. El contorno de ambas partes es desigual pues se refuerza la banda izquierda con un anillo que sobresale 2,5 cm sobre el cilindro de la parte derecha. Da la impresión de que el tallista ha tratado de realzar con más espacio la cara reservada a la imagen de Cristo Crucificado ${ }^{17}$.

Decora la cara derecha un círculo con el fondo rebajado y destacando sobre él una estrella de once radios tallada a bisel. El diámetro del círculo mide $13 \mathrm{~cm}$, con un pequeño umbo de $3 \mathrm{~cm}$, del que parten los once radios que miden $5 \mathrm{~cm}$.

Modillón $\mathrm{n}^{\text {o }}$ 5: de las dos molduras convexas superiores es más saliente la superior, pero se muestra algo más abultada la segunda. En este caso, de manera excepcional, el perfil del cuello bajante hacia la base es cóncavo y no convexo. Medidas del bloque saliente: A: 46; B: 38; C: 28; D: 8; E: 30; F: 8 (Lámina no 3).

La fina decoración que este modillón ofrece en ambas caras lo singulariza de manera muy sugestiva. Difiere del resto sobre todo en su disposición ornamental, aunque se asimile en todas las medidas a los más típicos ejemplos del conjunto. Varios datos descartan cualquier hipótesis que pretendiera afirmar que no es un modillón concebido para soporte, sino una lápida reutilizada para tal función ${ }^{18}$. Por su semejanza creemos que forma parte clara del conjunto de modillones medievales, aunque lo singularice un diseño que parece inspirado

16. En muchos relieves, pinturas murales o miniaturas románicas, por medio de expresiva sinécdoque, basta la presencia de la diestra divina para significar la acción transcendente: mano creadora, que bendice o condena. Como ejemplo, en el capitel visigótico del Sacrificio de Isaac, de San Pedro de la Nave, la diestra divina es de muy similar tamaño y disposición a la de Elizmendi.

17. El saliente en forma de corona que circunda la cara del bloque figurada con el Crucificado, recuerda la disposición y el perfil discoideo de las claves pinjantes, habituales a partir del gótico, aunque en este caso la coincidencia sea puramente casual, pues no avalan la idea ni el estilo de la talla ni el contorno, que no es circular sino oblongo.

18. Como se ha indicado, en la Carta Arqueológica de Álava, p. 393, no 9122, este modiIlón es interpretado como el recorte de una estela romana, al igual que otros 25 fragmentos intestados claramente romanos. 
Lámina 3. Modillones 6: estrella; 5: helicoidal; 4: estrella y crucificado;

3: cruz.

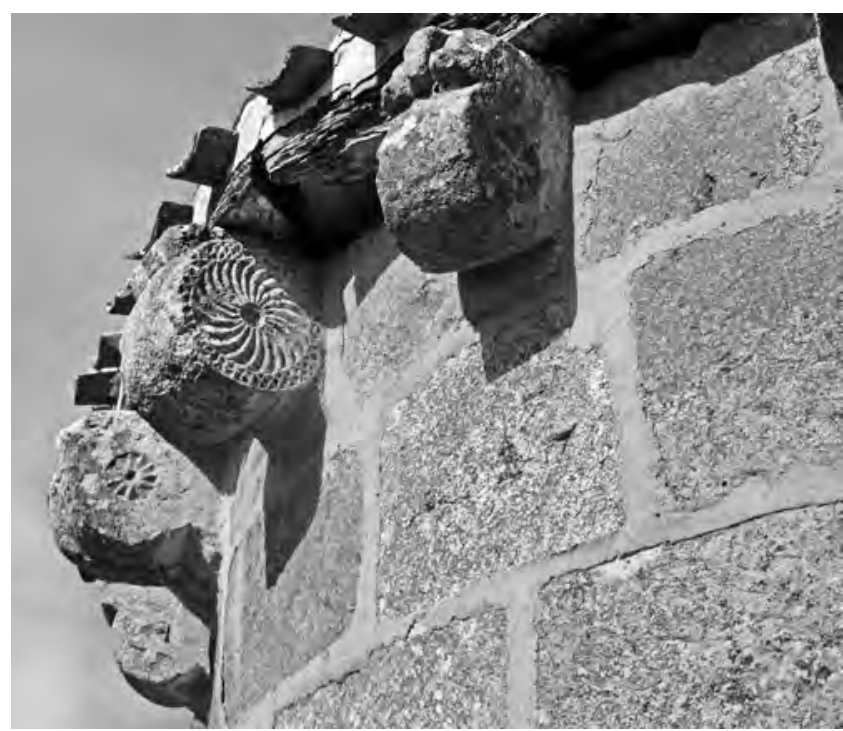

en los modelos de muchas estelas o lápidas romanas del entorno, posible modelo de los tallistas, en piedra o madera, durante un dilatado abanico temporal.

En cuanto al tratamiento del bloque, tiene la peculiaridad de que en el ápice frontal sobresale un pequeño levante curvo, de $8 \mathrm{~cm}$ de altura. Debido a la disposición de tal esquina superior se anula la posibilidad de que se trate de una estela discoidea, compuesta de círculo y base, a modo de cuello algo más estrecho. Sin embargo la ornamentación contribuye a sugerir una neta circunferencia. También hacia la base de apoyo en el muro, presenta un perfil curvado, en este caso del tipo cóncavo en caveto, que baja unos $8 \mathrm{~cm}$. Salvo estos dos extremos el bloque, en su gran cilindro saliente, desarrolla por ambas caras unas muy cuidadas composiciones geométricas. Las circunferencias de ambos lados son precisas en la configuración de sus sucesivos diámetros concéntricos y los diseños de orlas o de líneas curvas están regidos por un cuidadoso compás.

La circunferencia de la cara izquierda alcanza los $33 \mathrm{~cm}$ de diámetro, comprendiendo primero una orla dentada de $3 \mathrm{~cm}$ de espesor, en que se contabiliza una sutil corona de 23 puntas, después un círculo interno de $27 \mathrm{~cm}$, donde se dibuja una hexapétala bien trazada con seis pétalos, cada uno de $12 \mathrm{~cm}$ de longitud. Aparecen realzados sobre el rehundido del plano de fondo.

La cara derecha es equivalente en su perfil, dominado arriba por el ápice descrito, y con el apoyo de abajo en caveto. La circunferencia ornamentada alcanza 33,5 cm de diámetro, y su perfil curvo, pese al desgaste de la arista, se muestra preciso y bien contorneado. Bordea el conjunto una cenefa de $4 \mathrm{~cm}$, en que se teje una cadeneta de rombos, ejecutada de manera cuidadosa, recor- 
dando la talla en madera. Podemos llegar a contabilizar una cincuentena de rombos encadenados, abarcando cada uno $2,5 \mathrm{~cm}$ de alto por 1,5 de ancho. El disco central resulta muy expresivo, incluyendo en su diámetro de $25,5 \mathrm{~cm}$, una rueda helicoidal formada por 21 radios curvos dextrógiros, partiendo de un eje central de $5 \mathrm{~cm}$ de diámetro. En torno a él dinamizan la corona circular, ancha de $10 \mathrm{~cm}$, los 21 radios, que se agrupan más densamente en el tercio superior, abriéndose algo más su abanico en el resto.

Modillón no 6: va coronado por un listel no muy espeso, bajo el que se despliega una abultada moldura convexa y hacia la base se curva en gola. En el frente de la franja recta superior se advierte un rehundido en que se reconocen tres elementos separados, como un esbozo de figuración no concluida. Un saliente central de mayor tamaño tiene forma trapezoidal, curvada en su cima, que podría recordar el esbozo de una cabeza, no definida. De manera simétri$\mathrm{ca}$, a ambos lados la flanquean dos protuberancias, como un remedo de los brazos. El inacabado o la indefinición impiden llegar a algo más concluyente. Medidas del bloque saliente: A: 46; B: 32; C: 21,5; D: 12; E: 25; F: 9.

El modillón presenta decoración en ambas caras, secundando la curva de la abultada moldura central. En la cara izquierda muestra el ya citado círculo con el fondo rebajado y destacando sobre él una estrella de ocho radios tallada a bisel. El diámetro del círculo mide $13,5 \mathrm{~cm}$, y cada radio $6,5 \mathrm{~cm}$. En la cara opuesta se dispone de manera simétrica un círculo equivalente, también de ocho radios labrados a bisel, de tamaño ligeramente menor: el diámetro del círculo mide $13 \mathrm{~cm}$, y cada radio $6,5 \mathrm{~cm}$.

Modillón no 7: guiándonos por la posición de la saetera cegada, que queda debajo, a la altura de la tercera hilada desde arriba, concluimos que este es el modillón situado en el eje central de ábside. Su moldura superior, algo curvada, es mucho menor y menos saliente que la inferior, que destaca por su perfil abultado, y reposa sobre pequeña gola. En la cara izquierda de la moldura gruesa se practicó un círculo inciso, de $14 \mathrm{~cm}$ de diámetro, en cuyo interior se advierte una tira casi vertical de $6 \mathrm{~cm}$ de longitud y $2 \mathrm{~cm}$ de anchura. Por comparación con la misma cara del modillón $\mathrm{n}^{\circ} 9$ podemos adivinar un intento fallido de realizar una rueda o un cruciforme inscrito en un círculo que no se ha completado, se ha desechado, o bien se ha borrado. La otra cara no ofrece decoración. Medidas del bloque saliente: A: 42; B: 32; C: 32; D: 8; E: 25,5; F: 8,5.

Modillón no 8: El bloque, aunque dispar por su temática y trazado, encaja dentro de las dimensiones habituales del conjunto. Medidas del bloque saliente: A: 41 ; B: 38,5; C: 24 . Resulta excepcional en su configuración volumétrica, figurando un prótomo animal, con caracteres de figura exenta. Se diferencia completamente de los canes, en que las representaciones, sean animalísticas o humanas, surgen como un relieve apoyado en una referencia dorsal, una moldura que habitualmente tiene forma de nacela o caveto, a quien se confía la función de soporte de la cornisa. En el caso que nos ocupa es el dorso del ani- 
mal quien sostiene el peso superior. La cabeza se prolonga unos $25 \mathrm{~cm}$ en su medida mayor, mientras que de los elementos separados: orejas, cuello o patas, no sobrepasa ninguno los $10 \mathrm{~cm}$.

Su volumen sugiere de manera expresiva la cruz del espaldar, los recios flancos, cabeza con orejas alzadas y hocico largo, cuello robusto y unos muñones en que se abrevian las patas delanteras. Nunca fueron acabadas, pero aún así, aparecen desgastadas. El deterioro afecta sobre todo al hocico, que quizá acabase en trufa, pero está roto. En la cabeza sobresalen las dos orejas paralelas, enhiestas y puntiagudas. Bajo ellas se curva el testuz, sugiriendo unos ojos bastante frontales, e iniciando un progresivo adelgazamiento hasta el hocico, mellado. Dado su modelado sumario y su desgaste, no es concluyente su identificación zoológica, pero la disposición de las orejas triangulares, la amplitud maxilar y el morro alargado, apuntan como mejor referencia a un cánido y quizá, dada su prestancia, pueden sugerir el aspecto imponente del lobo: el canis lupus.

El lobo ha sido en otros tiempos un peligro grave para el ganado de la sierra contigua. En el siglo XVIII se celebraban rogativas muy animadas y misas por el buen éxito de las batidas de lobos en la ermita de la Virgen de Iturrieta, antigua parroquia del despoblado del mismo nombre. También en Elizmendi, ermita de Kontrasta, se celebraban misas solicitando gracias de todo tipo incluso: "para el buen éxito de las batidas contra los $\operatorname{lobos}^{\prime 19}$ (Lámina nº 3).

Modillón $\mathrm{n}^{\text {0 9: }}$ de las dos molduras convexas superiores, la segunda es no solo la más saliente, sino bastante más abultada, de forma que constituye un sólido rollo o rodillo. Como viene siendo habitual, hacia la base se curva una pequeña gola. Medidas del bloque saliente: A: 42; B: 40; C: 23; D: 12; E: 21; F: 9.

El rodillo central presenta decoración en ambas caras. Por el lado izquierdo se advierte el habitual círculo de poca profundidad de fondo, sobre el que se eleva un cruciforme o, si se prefiere, una rueda. Mide $14 \mathrm{~cm}$ de diámetro. Según un trazado simétrico, en ángulo recto se disponen los cuatro brazos, que miden $5 \mathrm{~cm}$,

19. VEGAS ARAMBURU, J.I., "Románico en Álava. Itinerarios...", p. 48: Elizmendi mantenía una cofradía con ordenanzas aprobadas en 1731 con un marcado matiz funerario. Se acudía en rogativas el 3 de Mayo, 22 y 23 de Junio y 10 de Julio. Además se celebraba el día de San Roque y los de Larraona acudían a Elizmendi el 4 de Julio. Se celebraban misas solicitando gracias de todo tipo, incluso "para el buen éxito de las batidas contra los lobos". No será necesario insistir en la amenaza que suponían estos animales para los pastores y ganaderos de las comarcas montañosas de Álava, como de otras regiones cercanas. Lo testimonian la presencia de loberas, sobre todo en el oeste alavés, pero también las referencias de la toponimia de Entzia-Urbasa o Arana. Los lobos son citados por el historiador del siglo XVIII Joaquín José de Landázuri entre las especies campestres, LANDAZURI, J.J., "Historia civil de la M.N. y M.L. Provincia de Álava", cap. XVI, en Obras históricas sobre la provincia de Álava, vol. II, p. 99, Diputación Foral de Alava, Vitoria, 1976. También: "Villa de Contrasta", en Los Compendios históricos de la Ciudad y Villas de la M.N. y M.L. Provincia de Álava, cap. IV, Obras históricas sobre la provincia de Álava, vol. I, pp. 362-365, Diputación Foral de Álava, Vitoria, 1976. 
en torno a un pequeño círculo de solo $1 \mathrm{~cm}$ de diámetro. La cara derecha muestra un círculo con el fondo rebajado y destacando sobre él una estrella de ocho radios tallada a bisel. El diámetro del círculo mide 13,5 cm, y cada radio $6 \mathrm{~cm}$.

Modillón no 10: de las dos molduras convexas superiores, la segunda es igualmente saliente, pero su curva es mucho más abultada, constituyendo un sólido rodillo. Como viene siendo habitual, hacia la base se curva una pequeña gola. Medidas del bloque saliente: A: 49; B: 41; C: 23; D: 16; E: 24; F: 9.

El rodillo central presenta decoración en ambas caras. Por el lado izquierdo se ha excavado el círculo, sobre cuyo plano de fondo se eleva una estrella de once radios tallada a bisel. El círculo mide 13,5 cm de diámetro, con un pequeño aro central de $3 \mathrm{~cm}$ de máxima amplitud, y cada radio extendido $5 \mathrm{~cm}$. La cara derecha muestra el mismo tipo de círculo en que se reconoce una estrella de ocho radios tallada a bisel. Su diámetro mide $14 \mathrm{~cm}$, y cada radio $6 \mathrm{~cm}$.

En inmediata proximidad al límite del muro absidial por el norte, donde es cortado por la inserción del murete tardío de la sacristía, integrado por mampuestos, se advierte una piedra labrada, aunque fracturada. Se reconoce en su aspecto a la fina caliza paleocena, franca y blanca, de fácil y durable labra, que ha sido protegida de la intemperie, a diferencia de los canes y sillares del ábside, afectados por la lluvia, y el viento que les ha producido erosión y el nacimiento de líquenes. La parte que aflora de la piedra mide aproximadamente $18 \mathrm{~cm}$ de alto y $24 \mathrm{~cm}$ de ancho. Su borde izquierdo dibuja un segmento de círculo, bordeado exteriormente por una franja de $6 \mathrm{~cm}$, en la orla interior se curva otra franja de $4 \mathrm{~cm}$ que contornea un círculo excavado, que mediría $14 \mathrm{~cm}$, sobre el que se destaca un diseño de rueda o cruz en torno a un círculo inciso, de $3 \mathrm{~cm}$ de diámetro. Los brazos del cruciforme miden $5,5 \mathrm{~cm}$ de largo y 3,2 cm de ancho. Todo ello podría reconstruirse formando un disco de aproximadamente $22 \mathrm{~cm}$ de diámetro, dejando espacio al trazado concéntrico del círculo excavado descrito. En conclusión, todos los datos lo equiparan a nuestros modillones, y su trazado ornamental coincide exactamente con la cara izquierda del nº 9, el anteúltimo.

\section{Consideraciones sobre los peculiares modillones de ornamentación bifacial}

La disposición habitual de los canes o canecillos románicos es la de un apoyo saliente, que emerge en el extremo superior del muro, ofreciendo una superficie en que descanse la cornisa o el extremo del alero de la cubierta. Vistos de perfil tienden a adoptar la forma cóncava del caveto, o la ondulante de la nacela, albergando en su concavidad una cabeza, objeto o figura. Cuando el apoyo se realiza sobre un bloque convexo, como una repisa redondeada en bocel, no hay lugar para albergar la figuración. Prácticamente esa forma es incompatible con ella, de modo que, cuando se dispone, determina que los canes sean habitualmente lisos.

En Elizmendi, el formato característico de los nueve modillones discoideos, todos menos el prótomo animal, se organiza con triple curva en cascada men- 
guante, pero sobredimensionando la curva central que le da la forma discoidea. El tramo vertical que ocupa el disco supone en una mayoría de casos la mitad o más de la altura del modillón: así es en los no 2, 4, 5, 6, 7 y 8. Su apariencia es la de un grueso rodillo sostenido por dos molduras más débiles, la superior y la inferior. El espesor de ese rodillo oscila entre los 22 y los $32 \mathrm{~cm}$, con una media de $26 \mathrm{~cm}$.

La única solución coherente para incorporar decoración a este formato de modillón convexo, en terminología antigua: óvolo, es aplicarla a ambos laterales planos. Así es como se ha procedido en los modillones de Elizmendi, coincidiendo con la manera de ornamentar las estelas discoideas, especialmente abundantes en toda el área vasco-navarra. La convergencia con éstas no solo estriba en la forma de disco, sino también en las zonas decoradas e incluso en los mismos motivos ornamentales. Tanta convergencia en lo formal y decorativo conduce inicialmente a pensar en coincidencia de función. ¿Cabría pensar que estos modillones fueran estelas discoideas, o bien reutilizadas, o bien copiadas para readaptarlas a la función sustentante? La respuesta es concluyente: ciertamente no.

En los modillones debe primar su robustez para poder ejercer como soportes, por ello su espesor se sitúa, como se ha indicado, entre los 22 y $32 \mathrm{~cm}$, mientras el diámetro imaginario se sitúa entre los 20/30 cm. En cambio el disco de las estelas discoideas es normalmente más dilatado en sus caras, pero no alcanza ni la mitad de su espesor ${ }^{20}$.

Además, un examen de los diez canes labrados, revela inmediatamente que su formato no es el de un disco apoyado en un cuello y un soporte, sino el de una repisa. Es decir, que siempre sobresale la parte superior y decrece en la inferior. No tiene sentido imaginar estas piezas en posición vertical, sino horizontal, descansando sobre la breve base para ofrecer la superior como saledizo sustentante (Lámina no 4).

En ciertas descripciones publicadas se ha pretendido identificar al modiIlón $5^{\text {o }}$ como una lápida o estela reutilizada, a lo que se alude en las notas 5 y 18. Nos referimos a la esvástica plurirradial que, dextrógira en el modillón, puede hallarse casi igual en la lápida romana levógira, intestada en el muro a pocos metros. Merece la pena una comparación detallada que demuestra que hay clara inspiración, pero no una copia literal (I.r.: lápida romana; modillón: m.). Diámetro general: I.r.: 25,50 cm; m.: 33,5 cm. Cenefa exterior: I.r.: $2 \mathrm{~cm}$; m.: 4 cm. Círculo radiado: I.r.: 21,50 cm; m.: 25,5 cm. Umbo central: I.r.: 4

20. Tomando como referencia las medidas que ofrece Frankowski sobre estelas de Navarra y algunas de Iparralde o País Vasco de ultrapuertos, la media de grosor puede situarse en torno a los $11 \mathrm{~cm}$ y el diámetro medio oscila entre 30 y $45 \mathrm{~cm}$. FRANKOWSKI, E., Estelas discoideas de la Península Ibérica, Madrid, 1920, reedición en ed. Istmo 1989, primera parte. El aspecto volumétrico de las piezas cambia completamente en ambos casos, y eso solo atendiendo a los discos, sin reparar en la configuración típica de los soportes verticales de las estelas. 


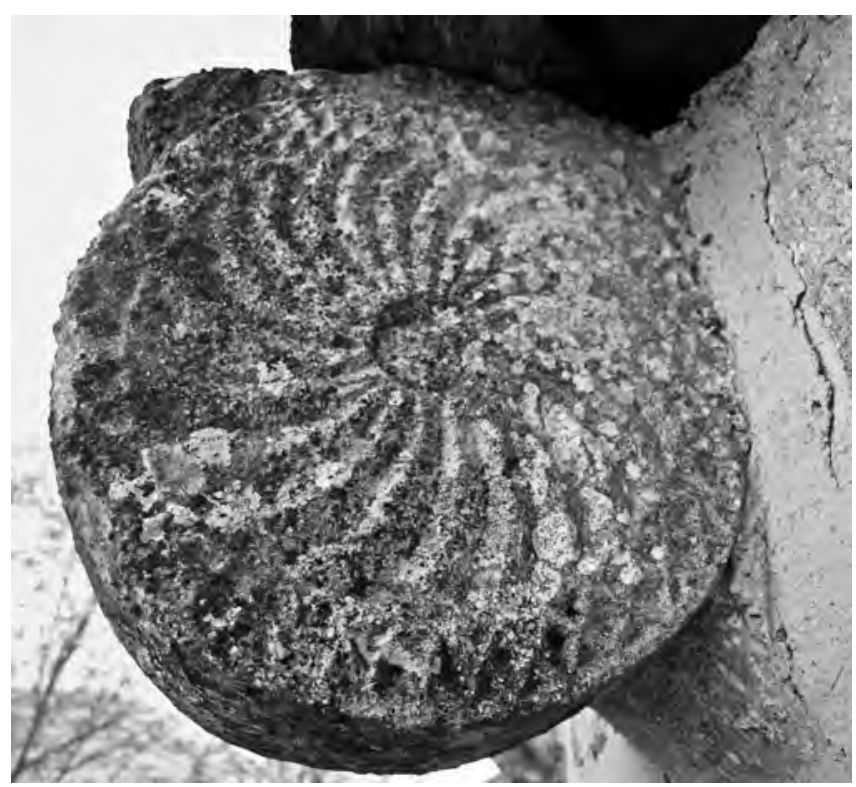

Lámina 4. Modillón 5, cara norte: rueda helicoidal muy similar a las de las lápidas romanas.

cm; m.: 5 cm. Número de radios: I.r.: 22; m.: 21. Dirección: I.r.: levógira; m.: dextrógira.

Poniendo como ejemplo este modillón $\mathrm{n}^{\mathrm{0}}$ 5, resulta inviable que los que labraban los modillones hayan recortado el motivo de una lápida, y sobre todo que les haya resultado coincidente en el reducido círculo un equidistante motivo por el otro costado.

Si se pretendiera pensar en la reutilización de una estela discoidea, nunca existiría el saliente en forma de pequeño cuerno superior, volando sobre la curva. El disco hubiera exigido su eliminación para redondear del todo el perfil curvo, que ronda los 190/200 . Casi todas las estelas discoideas conocidas sobrepasan en su curva los $280^{\circ}$ de circunferencia, y no pocas alcanzan los $300^{\circ}$. Otro de los modillones, el no 9 o anteúltimo, visto desde la cara sur alcanza más de $220^{\circ}$, aunque con perfil curvo algo menor en la otra cara, pues la labra es algo irregular. El perfil curvo de otros Ilega también a sobrepasar los $200^{\circ}$. En cambio es menos marcado en el que representa al crucificado, que puede oscilar entre 150 y $160^{\circ}$.

Queda por tanto constatada la tendencia discoidea, pero sin función de estelas, de todos los modillones de Elizmendi, menos el que ostenta representación zoomorfa. Podemos concluir que los motivos de cruces, estrellas o discos solares son como los fonemas de un lenguaje muy antiguo, o mejor, como los ideogramas de un simbolismo perdurable. Podemos suponer que, en su nacimiento, tales signos estarían cargados de significado concreto, pero que a lo largo de la 
evolución del pensamiento han podido transformarse, recargarse o disolverse en cuanto al contenido significativo ${ }^{21}$.

\section{Análisis de la ornamentación bifacial geométrica en los modillones}

Modillones con ornamentación geométrica: nº 5, lado norte: disco con 21 radios curvo girando a partir del centro, del tipo esvástica dextrógira. El umbo central mide $5 \mathrm{~cm}$ de diámetro, y todo se encuadra dentro de una cenefa de rombos seriados, de $4 \mathrm{~cm}$ de ancho. Hay insistencia en superponer círculos concéntricos: el borde del disco, la corona anular y el botón central. El ritmo va marcado por dos factores: el encadenamiento de rombos y sobre todo el giro curvado de la esvástica.

En la otra cara, la sur, del modillón no 5 también la ornamentación está cuidada. Aparece completamente trazado el círculo, rematado por una delgada cenefa de zigzag fino, en que pueden contarse 23 puntas exteriores. El disco va decorado con una hexapétala bien dibujada, sobresaliente unos $0,5 \mathrm{~cm}$ sobre el fondo.

El motivo más repetido es un círculo inciso donde se hace resaltar, mediante el tratamiento de fondo realzado, una forma estrellada con ocho radios que parten del centro. Eso ocurre en los modillones: $\mathrm{n}^{\circ} 3$ en cara sur, $\mathrm{n}^{\circ} \mathbf{6}$ en ambas caras, $n^{\circ} 9$ y no 10, los dos en la cara norte. Su formato es idéntico. Sus diámetros reflejan una gran uniformidad, entre 13 y $14 \mathrm{~cm}$, y lo mismo en sus radios, que oscilan entre 6 y $6,5 \mathrm{~cm}$.

Otro motivo, que aparece dos veces, consiste en un círculo inciso en cuyo centro confluyen once radios, obteniendo por tanto una forma estrellada más densa que la anterior. Aparece en los modillones $n^{\circ} 5$ y $n^{0} 10$, ambos en la cara norte. El trazado de los radios no es muy exacto en su equidistancia. Parten de un pequeño círculo central de $3 \mathrm{~cm}$ de diámetro, y en ambos casos el diámetro del círculo es de 13,5 cm.

Observamos también el motivo cruciforme. Se muestra completo en la cara sur del modillón no 9 y solo esbozado en la misma cara del modillón $n^{0}$ 7. Ambos círculos tienen un diámetro de $14 \mathrm{~cm}$. El que está completo presenta como eje un pequeño círculo central de $1 \mathrm{~cm}$ de diámetro, del que

21. Varios de los motivos descritos en los modillones de Elizmendi aparecían ya en las lápidas romanas del tipo de las intestadas en la misma ermita o de las halladas en el entorno, y también esos motivos mantendrán su pervivencia en estelas ya cristianizadas, sobre todo las correspondientes al tipo discoidal, hasta la Edad Media e incluso hasta épocas relativamente recientes. Las mismas o similares formas han pasado a ornamentar otros objetos del Ilamado arte popular, como los kutxarros, o vasos de cuerno de vacuno realizados artesanalmente por pastores, con figuraciones e inscripciones grabadas, como los procedentes de Cicujano/Zekuiano, en el vecino valle de Laminoria. 
arrancan cuatro brazos en sentido perpendicular y con forma de cruz. Cada brazo mide $5 \mathrm{~cm}$ de largo por 3,5 cm de ancho. El círculo del modillón 7 solo presenta acabado el brazo vertical superior, y mide $6 \mathrm{~cm}$ de largo, por $2 \mathrm{~cm}$ de ancho. Este mismo motivo se reconoce en un disco intestado en el muro de mampostería de la sacristía, probablemente otro modillón que fue arrancado de su emplazamiento al adosar la sacristía. Aunque incompleto a nuestra vista, se percibe el círculo con el cruciforme, coincidente en medidas y aspecto con el descrito del modillón $\mathrm{n}^{\mathrm{0}}$ 9, pues mide $14 \mathrm{~cm}$ de diámetro, y en los brazos 5,5 cm de largo, por 3,2 de ancho, y el círculo central también presenta $3 \mathrm{~cm}$ de diámetro.

\section{Un prótomo zoomorfo, la representación de un lobo}

En el $8^{\circ}$ modillón se recurre a una configuración volumétrica, sugiriendo el prótomo de un animal, inacabado o muy deteriorado, el cuarto delantero de un mamífero cuadrúpedo que alza sus patas. Aunque borrosos, hay rasgos reconocibles: orejas puntiagudas, frente curva que recubre los ojos situados en la transición del frente a los costado y hocico triangular rematado en punta, que se muestra rota. No hay cuernos y orejas horizontales como en los vacunos, la cara no es tan larga y los ojos tan laterales como en los équidos, ni adopta las protuberancias y depresiones de la jeta del jabalí. Es un cánido. Optamos decididamente por considerarlo una representación del lobo, bien conocido por sus figuraciones antiguas y me-dieva-

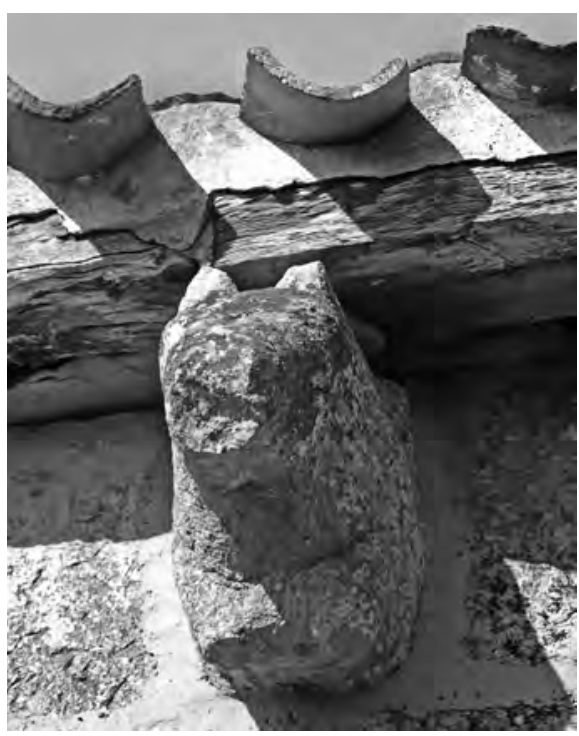

Lámina 5. Modillón 8: prótomo de un lobo. les, concretamente en múltiples canecillos románicos de la península y de toda Europa.

La excepción que supone esta figuración de lobo respecto a la serie discoidal indica que se supera el nivel de las representaciones geométricas, más simples y tradicionales, a la búsqueda de otro campo de expresión y significación. Ya no se trata de canteros restringidos a unos modelos de fácil copia con cincel y compás, para lograr una talla simple a dos planos. Se opta por una concepción de media figura de bulto, y con un tamaño significativo: el saliente del muro ocupa un marco volumétrico de 40x40x24 cm aproximadamente. Las formas son rotundas y sus puntos salientes aparecen redondeados, desgastados o pulidos por la intemperie. 


\section{Figuración de un crucificado}

En el modillón $n^{0}$ 4, hacia la cara meridional se contempla la otra figuración, también excepcional por su temática. En este caso es un bajorrelieve de 3,5 cm de espesor, adaptado a su contexto. Se reconoce la figura de un crucificado frontal, que con su cuerpo secunda la forma de la cruz, abriendo los brazos en posición horizontal y manteniendo las piernas juntas. Los elementos más cuidado son las manos, abiertas y grandes, detallando los dedos. En cambio el rostro ha sido picado, aunque se mantiene en torno a él el nimbo, y sobre la cabeza asoma el brazo superior de la cruz, ensanchándose según el perfil de cruz patada. La figuración cubre casi todo el espacio disponible y sus medidas máximas son: 39 cm de alto por $31 \mathrm{~cm}$ de ancho. No hay duda de su identificación iconográfica: sigue el tradicional modelo de Cristo crucificado, representado de manera simple e ingenua, deteriorado por la erosión y quizá por el vandalismo.

Aunque de lectura muy dudosa, en el listel superior del modillón $6^{0}$ se esbozan tres elementos salientes, muy difíciles de identificar pues, o no están acabados o la erosión ha borrado sus rasgos. Hay un elemento central con forma trapezoidal y a los lados dos salientes informes. Se ha especulado sobre la posible representación rudimentaria de una cabeza y dos manos, pero no hay suficientes referencias para su identificación.

La citada aspillera marca el centro original del ábside, ahora incompleto en su visión, por la sacristía intestada en el lado norte. Comprobamos que el modiIlón no 7 ocupa el centro de ábside. No es casual que los modillones más expresivos en cuanto a su ornamentación sean los tres que flanquean desde cada lado al $\mathrm{n}^{\mathrm{0}}$ 7, aunque éste tenga inacabado su motivo cruciforme. Quedan hacia la mitad sur tanto el modillón $n^{0} 5$, con la hexapétala y la esvástica, como el $n^{0} 4$ que muestra el Crucificado. En cambió en el sector septentrional destaca el prótomo de lobo, quizá colocado allí por su carácter negativo y amenazador ${ }^{22}$.

\section{Continuidad en las tradiciones de labra de lápidas funerarias}

Cuando se trata, como en Elizmendi, de volúmenes discoidales, es normal comparar sus modillones con las antiguas tradiciones reconocibles en las estelas discoideas, que se remontan a época prerromana, o romana, y que perduran hasta nuestros días en ciertas comarcas. La comparación es favorecida por el con-

22. De manera genérica el lobo es considerado un animal infernal, funerario y andrófago, remontando a la antigüedad hasta Asiria al menos, donde ya es representado en las típicas tabletas. Se le colma de significaciones negativas, tanto en mentalidad cristiana moralista como por los mitos etnográficos habituales en Europa. LANDRY, J.M., El lobo, Barcelona, Omega, 2004. Es un devorador, tipificado como amenaza del castigo, como emblema de la voracidad e incluso del pecado de avaricia. Según oscuras tradiciones, algunas cofradías de canteros recurrieron al misterioso simbolismo del lobo para evocar uno de los grados de iniciación. 
texto funerario, siempre presente en Elizmendi por sus muchas lápidas romanas intestadas y por las sepulturas altomedievales. El caso es localmente frecuente: un círculo de quince kilómetros alrededor de Elizmendi agrupa conjuntos donde se han hallado muchas estelas o lápidas romanas de carácter funerario y ornamentación geométrica y astral: la ermita de San Miguel de Okariz, Luzkando, San Román de San Millán, el valle de Lana, sobre todo en Gastian y Larraona ${ }^{23}$.

El arraigo de tales tradiciones hizo perdurar, como en otros lugares la costumbre de las estelas discoideas bastante más allá de la Edad Media. Es sorprendente por ejemplo, la abundancia constatada en Iparralde, o País Vasco francés, incluso para los siglos XV al XVIII ${ }^{24}$.

\section{Parecidos y diferencias con los modillones de rollos}

A la vista de volúmenes cilíndricos encadenados en los modillones, es normal recordar los característicos modillones de rollos o modillones de lóbulos: una repisa que alberga en su hueco varios cilindros yuxtapuestos. Rara vez son todos iguales, pues suele destacar en tamaño el superior. Una referencia fundamental, escrita en 1936, corresponde a Leopoldo Torres Balbás ${ }^{25}$.

Según palpables ejemplos, el modillón de rollos atraviesa el Pirineo y desde el siglo XI alcanza al arte románico francés, con el nombre de modillons à co-

23. El inventario de las lápidas y estelas romanas en Álava, además de su interpretación epigráfica, se remonta a muchos años atrás: ELORZA, J.C., "Ensayo topográfico de epigrafía romana alavesa", Estudios de Arqueología Alavesa, 2. Vitoria-Gasteiz, 1967, pp. 119-186. ELORZA, J.C., "Estelas romanas en la provincia de Alava", Estudios de Arqueología Alavesa, 4, VitoriaGasteiz, 1970, pp. 235-274. GARCíA, E., SÁENZ DE BURUAGA, J.A., SAN VICENTE, J.I., "Estelas y lápidas romanas inéditas del Este de Álava", Estudios de Arqueología Alavesa, 12. Vitoria-Gasteiz, 1985, pp. 343-363. Pueden contabilizarse en torno a 250 estelas y lápidas romanas identificadas en Álava, y muchas de ellas reutilizadas; de ellas el 75\% del total se concentra en edificios de culto de la Llanada oriental y el Valle de Arana.

24. La obra de referencia tradicional es la de COLÁS, L., La tombe basque, Bayonne 1923. También pueden encontrarse importantes colaboraciones con estudios sobre las estelas discoideas de toda la península en la segunda parte de libro ya citado: FRANKOWSKI, E., Estelas discoideas de la Península Ibérica, reedición en ed. Istmo 1989, segunda parte, incluyendo bibliografía. Para actualizar la temática puede acudirse a los Congresos Internacionales sobre Estelas Funerarias, como el V, celebrado en Soria en 1993, y el VII de 2002 en Santander. En concreto afecta al área de nuestro estudio el artículo de LEIZAOLA CALVO, F., "Estelas discoideas en las sierras Andía, Urbasa, Entzia y en sus inmediaciones (nueva aportación). NavarraÁlava", en Actas del VII Congreso Internacional de Estelas Funerarias, Santander, 2002, t. III, Santander 2004, pp. 937-949. De manera reiterada se verifica la constante aparición en las estelas de una serie de motivos característicos de larga duración. AZKARATE GARAI-OLAUN, A., GARCÍA CAMINO, I., Estelas e inscripciones medievales del País Vasco (siglos. VI-XI), I. País Vasco Occidental, Bilbao, Universidad del País Vasco, 1996.

25. TORRES BALBÁS, L., “Los modillones de lóbulos. Ensayo de análisis de la evolución de una forma arquitectónica a través de diez y seis siglos", en Archivo español de arte y arqueología, núm. XXXIV, 1936, pp. 1-62 y 20 láminas. 
peaux, tal como señalaron Émile Mâle, Camille Enlart, J. Puig y Cadafalch, etc. Gómez Moreno precisó la denominación como "modillones de rizos", atendiendo al tipo peculiar al que se refieren los citados autores. Georges Marchais desmontó la hipótesis formulada por Viollet-le-Duc de que procedieran de técnicas de carpintería, copiadas en la piedra, para apuntar a su utilización en la mezquita de Córdoba derivando de temas bizantinos.

Con un razonamiento conclusivo y múltiples ejemplos, Torres Balbás afianza la teoría de su origen romano que evolucionó ya desde época de Augusto $^{26}$. Cita los pasos comprobados en monumentos singulares: la Maison Carrée de Nimes, el templo de Vespasiano y Tito en el foro de Roma, el pórtico del Panteón, obra de Adriano, la rotonda de Baalbek, la columnata de Apamea, el arco de triunfo de Dugga, la scaenae frons del teatro de Mérida, las termas de Diocleciano en Roma, etc. Tales modillones tienden a dibujar una $S$ en sus laterales, y en ellos aceptará ornamentación floral o geométrica. En la cara frontal aparece a veces una faja vertical intermedia, o se adorna con acantos e incluso con cabezas humanas. Con diversas variaciones aparecerá en Bizancio y en la arquitectura paleocristiana y altomedieval. Ahí se acoplarán temas decorativos populares: rosáceas, entrelazos, cruces, o ruedas de radios helicoidales. Torres B. (pp. 26-36) presenta ejemplos de ménsulas de antiguas basílicas: rueda de hélice procedente de Henchir-el-Beguer, Argelia, de hacia el año 400, otras con hexapétalas, del siglo VI, en Henchir Mziral y Henchir Gussa, y una cruz en Annuna.

El siguiente paso corresponde al arte visigodo, con ménsulas cuyos laterales lucen hexapétalas, rosetas, motivos estrellados, sogueados, cruces y ruedas heli-

26. De hecho, previamente al modelo romano, se halla la edilicia griega. La explicación más antigua de la posición y función de los modillones, corresponde evidentemente al gran arquitecto romano VITRUVIO, M.L.-P., De Architectura libri decem, Lib. IV, cap. II: Postea alii in aliis operibus ad perpendiculum triglyphorum cantherios prominentes proiecerunt, eorumque proiecturas simaverunt. Ex eo, uti tignorum dispositionibus triglyphi, ita e cantheriorum proiecturis mutulorum sub coronis ratio est inventa. Ita fere in operibus lapideis et marmoreis, mutuli inclinatis scalpturis deformantur, quod imitatio est cantheriorum; etenim necessario propter stillicidia proclinati conlocantur. Ergo et triglyphorum et mutulorum in doricis operibus ratio ex ea imitatione inventa est.(...) También explica que el vuelo que imprimen los modillones en el orden dórico, lo retoman en el jónico los dentículos: Ita uti autem in doricis triglyphorum et mutulorum est inventa ratio, item in ionicis denticulorum constitutio propriam in operibus habet rationem, et quemadmodum mutuli cantheriorum proiecturae ferunt imaginem, sic in ionicis denticuli ex proiecturis asserum habent imitationem. Itaque in graecis operibus, nemo sub mutulo denticulos constituit; non enim possunt subtus cantherios asseres esse. Finaliza el capítulo VII del mismo Libro IV precisando la función de los modillones, en la conjunción de los muros con las vigas sustentantes de la cubierta: Supra trabes et supra parietes traiecturae mutulorum parte quarta altitudinis columnae projiciantur; item in eorum frontibus antepagmenta figantur. Supraque id tympanum fastigii structura seu de materia conlocetur. Supraque eum fastigium, columen, cantherii, templa ita sunt conlocanda, ut stillicidium tecti absoluti tertiario respondeat. 
coidales. Abundan los ejemplos en Mérida, San Pedro de Balsemao en Portugal, y en otros monumentos dispersos ${ }^{27}$.

En el arte islámico pasa a los talleres de la Mezquita de Córdoba, empezando por la puerta de San Esteban, de cronología discutida pues serían, o de fines del siglo VIII si ya era el acceso a la primitiva mezquita, o de la ampliación de Abderramán II inaugurada el 848, ya vigente en la visita de Muhammad el 855, tal como reza la inscripción de su arco y dintel. Los modillones que enlazan los pilares superiores con las columnas de apoyo de las típicas arquerías del haram de la mezquita muestran ya rizos encadenados, pero los ornamentados más antiguos también deban quizá retrasarse hasta las ampliaciones de mediados del siglo IX ${ }^{28}$. Una interesante aportación, basada en hallazgos arqueológicos recientes, son los modillones de rollos con bellos vegetales decorando sus costados, procedentes de los aleros de la antigua Mezquita de Tudela, que Pavón cree obra de Muhammad ibn-Hasim al Tuyibí, gobernador de Zaragoza hasta 950 y aliado de Abderramán III, superando en calidad a los modillones cordobeses en el momento del mayor esplendor del Califato de Córdoba ${ }^{29}$.

Son de sobra conocidos los modillones de rollos de las cornisas de las iglesias mozárabes de San Miguel de Escalada, San Cebrián de Mazote, Santiago de Peñalba, San Miguel de Celanova, San Román de Moroso y Santa Leocadia de Helguera, siendo un foco muy significativo por su proximidad e influencia en la zona el de San Millán de Suso, en La Cogolla riojana ${ }^{30}$.

27. FONTAINE, J., El Prerrománico, trad. de L'Art Prérroman Hispanique, Zodiaque, (1973), Madrid, 1987, p. 225. Los cuatro modillones cúbicos que enmarcan la dedicatoria de Recesvinto en San Juan de Baños con fecha de 661, presentan ruedas solares en su cara interior, además de palmetas y águilas, foto 62 . Se trata de esvásticas de seis brazos y son levógiras. Las hexapétalas, son muy comunes en lápidas o estelas funerarias romanas, también pueden verse en una pilastra visigótica del Museo de Mérida, fig. 41. En la fig. 49 muestra el dibujo de una estela hispanorromana procedente de San Cebrián de Mazote (M.A.P. de Valladolid), coronada por una esvástica dextrógira de 17 radios, de factura similar a la intestada en el muro sudeste del ábside de Elizmendi. Fontaine insiste en la p. 142 en que ese disco y motivos similares de origen romano servirán de modelo a los escultores visigodos de fines del siglo VII.

28. PAVÓN MALDONADO, B., Tratado de Arquitectura Hispanomusulmana, IV, Mezquitas, Madrid, CSIC, 2009. pp. 265-267; ver sobre todo: fig. 11: puerta de San Esteban, fig. 18: modillones de la Mezquita; fig. 30: modillones de la Mezquita y de Madinat-al-Zahra.

29. PAVÓN MALDONADO, B., Tratado..., pp. 670-671, fig. 20-21.

30. MARTíNEZ TEJERA, A.M., El templo del monasterium de San Miguel de Escalada: 'arquitectura de fusión' en el reino de León (siglos X-XI), AEDATME, Madrid, 2005, pp. 199-202: señala los modillones de gran vuelo con 5, 6 y 7 lóbulos, generalmente el superior de mayor desarrollo que los restantes que reducen su diámetro progresivamente, y van decorados con ruedas solares y flores hexapétalas. Recuerda que también hubo modillones lígneos hasta de 8 lóbulos. Cita como fuente de procedencia los prototipos califales, que a su vez retomaron tradiciones geométricas pre-musulmanas. El mozarabismo de Suso parece confirmado, entre las fases menores premozárabe y protorrománica, por CABALLERO ZOREDA, L., "La iglesia de San Millán de la Cogolla de Suso. Lectura de paramentos 2002", Arte medieval en La Rioja: pre- 
Si las formas curvas escalonadas de los modillones de Elizmendi pueden evocar los modillones de rollos islámicos o mozárabes, las diferencias superan a las semejanzas. Los cilindros o rollos son finos y desde su origen cordobés suelen escalonarse en número a partir de cuatro, pero es frecuente encontrar seis o siete, incluso diez en San Miguel de Celanova. Vistos desde abajo, cuando en el arte mozárabe forman serie los modillones del alero, sorprende su uniformidad, tanto entre los modillones mismos como en la hilera de rollos superpuestos de cada uno.

Además, desde el origen cordobés cruza perpendicularmente el centro de los rollos una banda, a veces con decoración destacada. Esta faja también suele parecer en los modillones à copeaux del románico francés. En las variaciones propias de la figuración románica, ha sido frecuente sustituir esa faja por una figura esculpida, animal o persona, que se encuentra respaldada por los rollos superpuestos. Esto ocurre incluso en ejemplos de comarcas alavesas, como es el caso de tres canecillos de Santa María de Tobera, y de los ejemplos en Añes, Miñano Menor, Valluerca, ermita de la Virgen del Campo de Maestu, además de los treviñeses de San Vicentejo y Moraza. Sorprende encontrar en ellos, tanto la versión simple de tres rollos superpuestos, como otras de seis, e incluso de más de veinte en ejemplares de Santa María de Tobera, sirviendo de fondo escalonado a figuraciones humanas. Muestran especial robustez e indicios de antigüedad los modillones de triple rollo que se ven en el ábside de San Julián y Santa Basilisa de Villanueva de Valdegovía ${ }^{31}$. Pero la fórmula de Elizmendi es otra.

\section{Similitudes del Crucificado con otros relieves}

Rastreando la bibliografía, pueden hallarse algunas figuraciones de crucifijos o personajes, que pueden considerarse paralelas en su tratamiento ${ }^{32}$.

rrománico y románico: VIII Jornadas de Arte y Patrimonio Regional, Logroño, 2002, IER, Logroño, 2004, pp. 13-94.

31. Ver la ya citada Euskal Erromanikoaren Entziklopedia - Enciclopedia del Románico en el País Vasco, III, 2011, pp. 1553-1556.

32. SEPIÈRE, M-Ch., L'image d'un Dieu souffrant (IXe-Xe siècle). Aux origins du crucifix, París, Cerf, 1994, pp. 109 y 137-142: El arte irlandés incorpora tempranamente el Crucificado frontal, destacando sobre una estela o una gran cruz. La silueta de Cristo aparece siempre muy dependiente del trazado de la cruz. La serie se inicia con la Estela de Duvillaun (c.700), con un crucificado desnudo, de rasgos simples, y de miembros muy adaptados a la cruz, o con las cruces de Killamery, la cruz meridional de Clonmacnoise y con el zócalo de la cruz de Moone, todas en torno al siglo VIII. Se refina el modelado y la postura en los crucificados de las placas de marfil del díptico Harrach, poco posterior al 800, de la Walters Art Gallery de Baltimore, y del Museo Merseyside County de Liverpool, que ya corresponden al siglo IX. Ya de pleno siglo IX la bella placa de marfil de la catedral de Narbona y algo posterior, aunque de talla más ingenua, el del díptico de Rambona. Otra comparación más tardía lleva a una iglesia landesa de peregrinación: HORVAT, F., PASTOUREAU, M., Figures romanes, Seuil, París, (1 ${ }^{a}$ ed. 2001), 2007, en la foto de la p. 142 presentan una crucifixión románica, con cinco figuras, situada en un bajorrelieve del ábside de la iglesia de Saint-Paul en Saint-Paul-les-Dax (Landes), obra del 


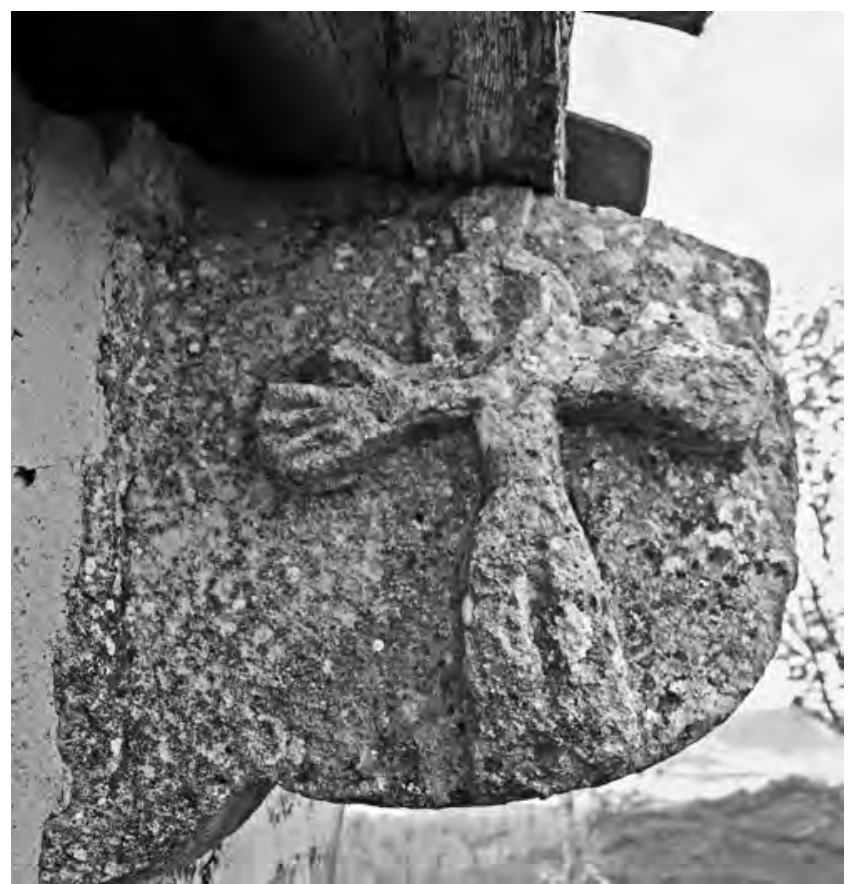

Lámina 6. Modillón 4, cara sur: Cristo Crucificado de talla ingenua.

Saliendo de Villatuerta hacia Estella, en la Cuesta del Moro, se sitúa la ermita de san Miguel, resto del antiguo monasterio benedictino, ya desaparecido, que fue donado en 1062 a Leire por el rey Sancho el de Peñalén. Se esgrime como dato para su construcción la inscripción empotrada sobre la puerta meridional -ahora en el Museo de Navarra-, que cita como obispo a D[omi]no Blascio y como rey a D[omi]no Sancio. El debate surgió por una doble coincidencia

primer tercio o de mediado el XII. La cruz es simple, patada. Cristo barbado, impertérrito, de manos grandes, tronco y piernas en prolongación, paño anudado y sobre la cabeza de Cristo no hay nimbo pero sí una crucecita patada de tres brazos, Los caracteres primitivos y toscos se acusan más en el crucificado que en las demás figuras. Acercándonos al País Vasco, escasean las comparaciones. Ver AZKARATE GARAI-OLAUN, A., GARCÍA CAMINO, I., Estelas e inscripciones medievales del País Vasco (siglos VI-XI), I. País Vasco Occidental, Bilbao, Universidad del País Vasco, 1996; en pp. 241-243 describen una estela tabular, procedente de la necrópolis de Ranes, Zierbena, Bizkaia, con un bajorrelieve representando a un hombre sobre cuya mano diestra apoya una cruz griega, mientras apoya la otra sobre su pecho. Talla a dos planos con perfiles recortados y dibujo simplificado. La mano diestra es exageradamente grande y quedan sin definir las facciones de la cara o pelo, como vestimenta se sugiere un traje talar. Schlunk lo databa entre los siglos IX y XII, los autores en el IX. Otra figura humana de rasgos simples en su composición se muestra en otra estela de la necrópolis de Iturreta, cerca de Markina, Bizkaia, pp. 230-233, también fechada entre los siglos IX y X. 
al coexistir el rey Sancho II Abarca y un abad Blasco de Leire a la vez obispo de Pamplona, que permitiría fecharla entre 971 y 979, e igualmente Sancho de Peñalén y otro Blasco obispo en Pamplona, lo que sugeriría los años 1067 1076, es decir un siglo más tarde. Optaron por la cronología del $2^{\circ}$ tercio del siglo XI Biurrun, Gudiol y García Gaínza, mientras que, desde una aportación del P. Germán de Pamplona, seguida por Íñiguez y Soledad Silva, se optaba por el final del siglo X. Al menos la tradición de talla es prerrománica, pero pudo tener una larga perduración hasta los labores del románico. Interesa mucho destacar que el Cristo crucificado de Villatuerta coincide en rusticidad, esquematismo y detalles puntuales, con el de Elizmendi ${ }^{33}$.

Es también en la Merindad de Estella, próxima a Kontrasta, donde se van hallando más ejemplos de tallas de crucificados pétreos, sobre todo en despoblados, como los de San Pedro de Artanga, Gomacin (Puente la Reina), Montalbán (Zurucain) o de las iglesias de San Martín de Unx, Elía, Labiano y Zozaya ${ }^{34}$.

Uno de los casos de talla de crucificado ofrece el interés de proporcionar una datación ante quem. Merced a una excavación arqueológica en contexto funerario, fue encontrado el relieve de un crucificado, dentro de un silo amortizado quizá hacia 1160-1170 por la construcción de la iglesia románica del Santo Sepulcro de Torres del Río, que no dista más de 25 km en línea recta de Elizmendi. Se trata de una estela muy deteriorada, de $80 \times 23 \times 11 \mathrm{~cm}$, presentando en el anverso un Crucificado en talla a dos planos de rasgos sumarios señalados con simples incisiones, brazos rectos, apenas perfilada la cruz, con restos de aureola, junto a su pierna una rosácea de cuatro pétalos, y en el reverso, además de una silueta de crucificado aún más esquemático, elementos geométri-

33. La comparación más directa del Crucificado de Elizmendi conduce al relieve de San Miguel de Villatuerta, uno de los once altorrelieves esquemáticos que se hallaban intestados en los muros de la ermita, ahora en el Museo de Navarra. La figura de Cristo no marca más que un solo plano, equiparando con sus brazos horizontales una cruz dilatada pero de bajo relieve. El cuerpo, con túnica corta, es rígido, de brazos cortos rematados por palmas abiertas y desmesuradas, y con piernas esquematizadas. Algunos autores interpretan el conjunto de relieves como una expresión plástica del ordo visigodo para la partida del rey en campaña, lo que constituirían una novedad en la iconografía escultórica. Unánimemente son considerados todos ellos como las primeras manifestaciones escultóricas de la época medieval en Navarra. SILVA Y VERÁSTEGUI, S. de, Iconografía del Siglo X en el Reino de Pamplona-Nájera, Institución Príncipe de Viana, I.E.R., Pamplona, 1984, pp. 92-95. AAVV, Catálogo Monumental de Navarra II.**. Genevilla-Zúñiga, Institución Príncipe de Viana, Pamplona, 1983, pp. 651-654, lám. 675.

34. ZUBIAUR CARREÑO, F.J., "Estela discoidea procedente del desolado de Gomacin (Puente la Reina)", Cuadernos de etnología y etnografía de Navarra, no 29, Pamplona 1978, pp. 339-347. TABAR SARRÍAS, M.I., "Representación en piedra de crucificado", VI Congreso Internacional de Estelas Funerarias. Pamplona 1995, Cuadernos de etnología y etnografía de Navarra, no 66, 1995, pp. 629-633. 
cos incluyendo una estrella de siete puntas. Interesa destacar esta combinación de formas geométricas, rosetas y estrellas con el Crucificado ${ }^{35}$.

Aunque lo fragmentario y simple de esta y otras piezas no facilite la comparación, podemos encontrar bastantes puntos de coincidencia con el crucificado de Elizmendi, lo que puede afianzar un horizonte cronológico que encaja con las fases iniciales del románico.

\section{Valoración de los criterios de definición estilística y cronológica}

Además de los paralelismos en el relieve del Crucificado, no hay un apoyo concluyente para fijar una cronología. Valoramos la coincidencia o convergencia de indicios.

En las estructuras prerrománicas anteriores a 1050, lo más habitual es una cabecera plana, o en todo caso ultrasemicircular en su cara interna, como ocurre en el mozárabe. En Elizmendi aparece edificado ex novo un hemiciclo absidial, empleando sillares regulares muy ajustados y con hiladas continuas. Su altura y dimensiones son de los más reducidos de entre los hemiciclos medievales, claro signo de primitivismo y de simplicidad funcional. En total se puede calcular menos de $20 \mathrm{~m}^{2}$ de terreno construido, y unos $11 \mathrm{~m}^{2}$ de espacio interno desde el arco de la embocadura del ábside. Se ilumina apenas con una mínima aspillera que es una simple hendidura entre sillares.

La disposición y factura del ábside nos convence de que se han alcanzado los avances constructivos románicos, regularizando sillares sólidos para edificar la exedra absidial. Más que una técnica retardataria, se trata de los tanteos de una fase creativa temprana. La exigüidad del ábside, tanto por su altura como en su mínima capacidad interior, parece más próxima a ciertos modelos prerrománicos que al típico presbiterio románico que, a partir del arco triunfal, dispone un tramo recto precediendo a la bóveda de horno.

En las iglesias del arte románico pleno nunca encontramos como única iluminación del ábside un vano en que apenas puede entrar un brazo, sin remate superior ni marca alguna que lo señale, siendo solo una rendija desapercibida entre dos sillares. Tampoco se reconocen en los modillones de Elizmendi los tipos habituales de canecillos, ni en el volumen, ni en su ornamentación lateral, ni en los motivos que aparecen. Incluso el tratamiento que recibe el único modillón no discoideo, sino volumétrico figurando un zoomorfo, escapa al formato convencional de canecillo del arte románico pleno. Su volumen es compacto y rotundo, esbo-

35. Es una aportación de UNZU URMENETA, M., CAÑADA PALACIO, F., LABÉ VALENZUELA, F., "Iglesia del Santo Sepulcro de Torres del Río: estela funeraria", VI Congreso Internacional de Estelas Funerarias. Pamplona 1995, Cuadernos de etnología y etnografía de Navarra, no 66,1995, pp. 623-628. 
zado a partir del bloque prismático, propio de los balbuceos de la talla de bulto, por lo que a algunos les ha podido recordar el característico verraco prerromano.

En cuanto a los relieves esculpidos en los modillones, los geométricos no sirven mucho para precisiones temporales, dada su amplísima perduración, por tanto hemos indagado en los relieves figurados, como el Crucificado y el atlante animal, al parecer un lobo, en cuyo lomo reposa el cornisamiento, a la manera de los capiteles persas. Nada hay propio del románico lombardo ni en el aparejo, ni en los remates del muro. Por otro lado, son tímidos esfuerzos en un arte aún no consolidado, y por ello poco accesible a los nuevos modelos. En consecuencia, todo parece apuntar a un momento inicial del románico, que podría concretarse a fines del siglo XI o a lo más a comienzos del siguiente siglo. Puede ser coincidente con el momento del cambio de rito, desde el hispánico al romano, lo que resulta oportuno para esa datación. En Aragón, con Sancho Ramírez el rito romano se introdujo en 1071, y muy poco después en Navarra, mientras en Castilla se suele relacionar con el concilio de Burgos de 1080 o 1081.

En el valle de Arana, la más directa comparación nos conduce, $3 \mathrm{~km}$ hacia el SE, a la ermita de Andra Mari de Ullibarri Arana. Muestra estructura completa: nave única, portada realzada con sobrearco de ajedrezado, y ábside, éste ligeramente mayor que el de Elizmendi. Se inscriben en un periodo y estilo bastante similar, pero ciertos datos otorgan la precedencia temporal a Elizmendi, anclada en un contexto funerario secular. La aspillera más simple, y los robustos modillones de original tipología y relieves, bien geométricos o bien con tempranas figuraciones lo avalan. Aunque una relativa abundancia de referencias documentales parecía decantar hacia los valles occidentales el románico alavés más primitivo, estos dos ejemplos de Ullibarri Arana y de Elizmendi, pueden inclinar el umbral románico hacia los confines orientales, junto a Navarra.

El único apoyo documental es la donación a Irache del monasterio de Nuestra Señora de Elizmendi, efectuada por Doña Sancha Pedriz de Uztúniga en 1203, con suficientes datos de arraigo: un capellán, Elizmendi como apellido, posesiones de pastizales, huertos, viñas y molinos, para pensar que la institución y la construcción de la iglesia subsistían desde generaciones, quizá precediendo un siglo a la donación.

\section{A modo de epílogo}

Una triple perspectiva acompaña al arte románico y desde ella podemos juzgar al ábside de Elizmendi: la capacidad técnica, con una cuidada ejecución en cuanto a técnicas y materiales, la orientación estética, mediante un lenguaje estilístico en sus relieves, y la vía conceptual, vehiculando su mensaje. Para ello se hace necesario un proyecto, un promotor, sea poder secular o eclesiástico, unos artesanos/artistas, unos medios y una circunstancia apropiada. El proyecto y su realización pueden situarse a niveles muy diferentes en cuanto a pretensiones y alcance. 
El contexto histórico más probable apunta a la iglesia de un monasteriolo de patronato laico, quizá con los ancestros de Sancia Pedriz de Uztúniga, su poseedora en 1203, y no cabe duda de su arraigado carácter funerario, que desde la antigüedad había podido generar una costumbre para las inhumaciones medievales. Es ya muy común hablar de un protorrenacimiento medieval, que se manifestó en obras y edificaciones respaldadas por centros de poder político o eclesiástico, donde pudieron arraigar los resabios del arte clásico culto: ars praeclara. Pero en lugares excéntricos lo que afloraba es un arte popular, simple, prosaico, que algunos historiadores del arte denominaron ars humilis, o modus humilis. Puede conectarse con la caracterización del ars humilis por parte de Hans Sedlmayr, matizada por Hugo Brandenburg respecto a los inicios del Arte Paleocristiano y muchos ejemplos de la Antigüedad Tardía ${ }^{36}$.

El trazado de signos geométricos es un recurso expresivo muy antiguo. Los círculos, los esquemas radiales del tipo estrella y los cruciformes aparecen en monumentos pétreos desde épocas prehistóricas. Los arqueólogos, por comparación con el uso de signos similares en culturas primitivas, estudiados por los antropólogos, han buscado frecuentemente para su explicación las referencias a simbolismos ancestrales: cultos solares o astrales, ritos de fertilidad, de protección del grupo de los vivos o de los difuntos. Los modillones de Elizmendi, que no siguen a los modelos habituales de canecillos, sino que parecen improvisar un sistema rudo de soporte, basándose en las referencias directas de las estelas romanas, sugieren que aún se hallan en los balbuceos del nuevo arte románico.

Así que los modillones encajan bien en su simbología de viejas raíces cosmológicas cristianizadas sincréticamente, pero con un sello específicamente cristiano: el Cristo Crucificado, como protector de la gran amenaza real, etnográfica y simbólica del lobo. Podemos valorar la hipótesis de que esta figura de lobo constituye la primera muestra de una escultura volumétrica de toda Álava medieval. En otros lugares aparece, pero ya en una fase románica muy consolidada ${ }^{37}$.

Precisamente ambas representaciones se sitúan en las antípodas simbólicas: el Crucificado, junto con las pequeñas cruces y los signos luminosos astrales por el lado de la salvación, mientras que al lobo se le atribuyen connotaciones muy negativas, rapiña, ira, hipocresía, avaricia. Recordamos el texto evangéli-

36. Incluso BIALOSTOCKI, J., El Arte del siglo XV. De Parler a Durero, Madrid, Istmo, 1998, en pp. 360-367 retoma el término "Ars Humilis" aplicándolo al arte popular de la Baja Edad Media.

37. MALAXECHEVERRÍA, I., El bestiario esculpido en Navarra, Pamplona, Institución Príncipe de Viana, 1982. DURLIAT, M., "Le monde animal et ses représentations iconographiques du XIe au XVe siècle", Actes des congrès de la Société des historiens médiévistes de l'enseignement supérieur public, 1984, vol. 15, no 15, pp. 73-92. DUCHET-SUCHAUX, G., Bestiaire Roman, Tournus, Centre International d'Études Romanes, 1992. HERRERO MARCOS, J., Bestiario románico en España, Palencia, Cálamo, 2010. 
co en que Cristo compara los falsos profetas con lobos feroces (Mt. 7,15), y a continuación se alude a la oposición: Lobo artero / Oveja dócil, según Mt 10,16 o Lc 10,3: Yo os envío como ovejas en medio de lobos. Como colofón queda la alusión en diversos idiomas de que meterse en la boca del lobo es un terrible presagio, una amenaza del peligro mayor, la muerte ${ }^{38}$.

Nos inclinamos por fechas próximas al 1100: o en las últimas décadas del siglo XI o muy a comienzos del siguiente. Si se confirma esta datación, el sólido ábside de Elizmendi aparece como primicia adelantada del románico inicial en Álava, adoptando el modelo de ábside robusto y casi ciego, con modillones que parecen de inspiración espontánea, aunando arraigados atavismos geométricos con el esbozo ingenuo de un Crucificado y de un lobo, para plasmar las más antiguas figuraciones esculpidas de Álava medieval.

38. Respecto a la incidencia del lobo en la comarca montañosa en que se enclava Kontrasta, uno de los datos a considerar es la toponimia. Un bella hipótesis es aventurada por GARCÍA DE ALBIZU JIMÉNEZ, B., "Toponimia y lenguaje de Améscoa Alta", pp. 135-164 en: Onomasticon Vasconiae. Actas: III Jornadas de Onomástica, Estella, 1990, III. Onomastika Jardunaldien Agiriak, Euskaltzaindia, Lizarra-Estella, 2008. Sugiere en la p. 139: Sería muy aventurado, aunque no exento de cierta lógica, deducir que Ocharan [es decir: "valle de lobos"] pudiera ser la primitiva denominación del valle de Arana, tanto alavés como navarro. 